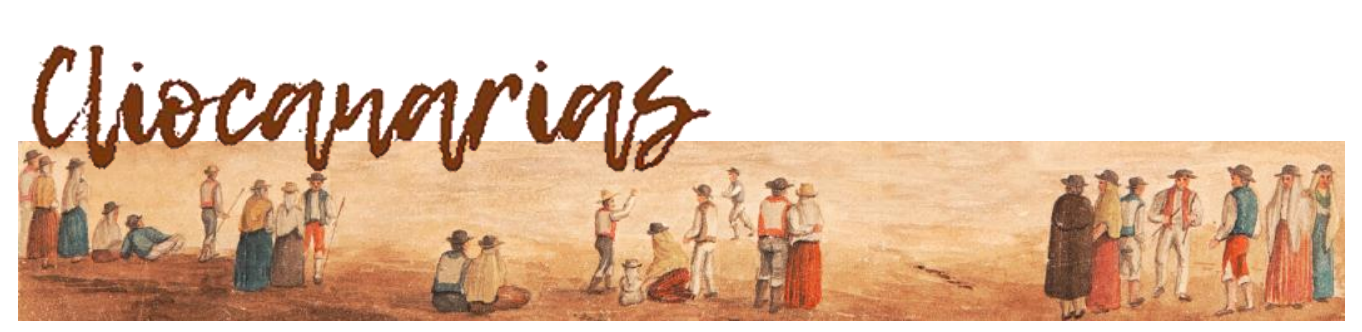

ISSN 2695-4494

https://doi.org/10.53335/cliocanarias.2021.3.12

\title{
LOS SOLDADOS DEL PRESIDIO DE GRAN CANARIA EN EL SIGLO XVI
}

SOLDIERS OF THE PRESIDIO OF GRAN CANARIA IN THE 16TH CENTURY

\author{
Manuel LOBO CABRERA*
}

\begin{abstract}
RESUMEN: El estudio de las milicias en el archipiélago canario ha sido un tema recurrente en la historiografia insular, abordada por distintos autores en amplitud y profundidad, al abarcar no solo la organización de las mismas sino incluso la estrategia y las armas utilizadas en la defensa, en momentos de peligro. Sin embargo, la presencia de los presidios en Canarias ha contado con menos opciones, al ser tropas profesionales, de paso y de refuerzo, que operan en las islas en momentos puntuales. El objetivo, por tanto, que perseguimos en este estudio es contraponer en el desarrollo de la defensa de la isla de Gran Canaria a los dos tipos de fuerzas que operaron en su territorio y sus características y consecuencias.
\end{abstract}

Palabras Clave: Gran Canaria, milicias, presidios, soldados, defensa, siglo XVI.

ABSTRACT: The study of the militias in the Canary archipelago has been a recurring theme in insular historiography, addressed by different authors in breadth and depth, covering not only their organization but also the strategy and weapons used in moments of danger. However, the presence of the presidios in the Canary Islands has had fewer options, as they are professional troops, passing through and reinforcement, that operate on the islands at specific times. The objective, therefore, that we pursue in this study is. in the development of Gran Canaria defense, to oppose the two types of forces that operated in its territory and their characteristics and consequences.

KEYwORDs: Gran Canaria, militias, presidios, soldiers, defense, 16th century.

\section{Introducción}

La defensa de la isla de Gran Canaria, después de concluida la conquista, recayó en los gobernadores nombrados por la Corona, pero sin articular nin-

* Catedrático de Historia Moderna. Universidad de Las Palmas de Gran Canaria. C. e.: mlobo@dch.ulpgc.es.https://orcid.org/0000-0001-9428-7740 
gún tipo de ejército ni de personal adiestrado para la misma, aunque desde fines del siglo XV se urdió la necesidad de construir una fortaleza en el puerto principal de la isla con el fin de que los navios se pudiera guarecer y estar a su abrigo. No obstante, y también desde bien pronto, la alarma que ocasionaban los corsarios que estaban subvencionados por los países enemigos de la Corona española, en especial Francia durante gran parte de la primera mitad del siglo XVI, generaron en la isla amenaza e inseguridad, en especial por la posición que ocupaban las islas en el Atlántico, que las convertía en una avanzadilla doble, ya que por un lado "aparentaban" ser un débil reducto a la vista de los enemigos, que las percibían como vulnerables, y por otro su posición en el camino hacia las Indias ${ }^{1}$.

Los nuevos colonos de la tierra tuvieron que afrontar, con escasos medios, los peligros que llegaban del mar, pues los asaltos a las naves mercantes eran continuos, así como el saqueo que intentaron los corsarios en ocasiones, razón por la cual las autoridades se vieron en la necesidad, con el apoyo de la Corona, de organizar con la población la defensa mediante, con una mínima organización, el alistamiento de hombres capaces de portar armas, así como la construcción y reparación de baluartes y la adquisición de armas y municiones para equipar a los milicianos.

La información que tenemos al respecto es escasa, pero suficiente para hacernos una idea de cómo la isla fue capaz de hacer frente a no pocas incursiones enemigas, que por distintos puntos intentaron atacar el territorio. Las autoridades, una vez que el peligro se acercaba, mediante los avisos de los atalayeros, tocaban y llamaban a rebato a los vecinos que, alarmados y en ocasiones muy mal armados, acudian a la llamada de las autoridades para impedir que los corsarios pudieran desembarcar, organizados sin un plan premeditado y con un rudimentario armamento ${ }^{2}$. Todo esto demostraba que la improvisación era la tónica general, razón por la cual la Corona, en función también de los continuos avisos que le llegaban desde las islas, respondiera a la preocupación a través de una serie de normas, contempladas en las reales cédulas, para organizar la defensa, a través primero de las milicias y luego de los presidios, aunque en Gran Canaria solo conocemos la presencia de dos a lo largo del siglo XVI, uno bastante escueto y otro más numeroso que generó más problemas que soluciones.

\section{Las milicias}

En Canarias, tanto por el coste que suponía para los Cabildos el tener que sostener tropas profesionales, o bien porque preferian tener a su servicio fuerzas defensivas formadas por las milicias, con el fin, quizá, de evitar a toda costa la injerencia de la Corona y de sus oficiales, apenas se contó con tropas regulares profesionalizadas a lo largo del siglo XVI, salvo excepciones.

Las milicias nacieron en Gran Canaria como reacción a la continua sensación de inseguridad ocasionada por los continuos ataques que sufrian sus

\footnotetext{
1 MARTÍnEZ RUIZ, E.: Los soldados del Rey: los ejércitos de la Monarquía Hispánica (14801700), Madrid, 2008, p. 762.

2 RODRÍGUEZ YANES, J. M.: Defensa, reclutas y donativos en Canarias (1500-1735), Santa Cruz de Tenerife, 2018, vol. I, p. 25.
} 
costas y los barcos mercantes que conectaban la isla con Europa, gracias al apoyo que los vecinos consiguieron de distintos gobernadores. Así que desde bien pronto, de manera espontánea, las autoridades de la isla, en connivencia con los vecinos fueron fraguando una especie de infraestructura militar, incluso antes de que se establecieran en la península, a pesar de los intentos sucesivos que se fraguaron en 1552 y 1562 de formar unas milicias locales ${ }^{3}$.

El hecho de que la isla de Gran Canaria fuera progresivamente creando un grupo militar, a la vez que iba fortaleciendo el sistema de defensas con el levantamiento de nuevos baluartes en su costa, hay que vincularlo al estado de guerra permanente que se mantenía con Francia durante el gobierno del emperador Carlos, que se acentuaría con el reinado de su hijo Felipe II. En efecto, así fue, de tal modo que el Concejo de la isla, a consecuencia de la continua presión de los corsarios franceses, se vio en la necesidad de formar a la población ante la posibilidad de un eventual ataque con la consiguiente invasión.

La mayor parte de los autores que se han ocupado del tema son de la opinión de que la movilización del personal masculino con el fin de adiestrarlos para la defensa mediante el cuerpo de milicias se inicia en la década de los cincuenta con el fin de configurar un ejército insular dependiente del consistorio.

En Castilla se utilizó para denominar este tipo de fuerza el vocablo milicias. Este término se aplicaba, dentro del tecnicismo militar, a ciertos cuerpos destinados a prestar servicios menos activos que los del ejército veterano del que fueron, en todo tiempo, eficaces y decididos auxiliares. Aunque estuviesen mandados o inspeccionados, como ciertas fuerzas irregulares actuales, por oficiales del mismo ejército.

Estas milicias durante casi todo el siglo XVI se convirtieron en el mejor instrumento para convocar a una fuerza dispersa por toda la isla y convertirla en una hueste. Los autores señalan en dicho período la existencia de dos tipos de milicias, de las cuales la insular era la adscrita a la propia demarcación de Gran Canaria, que hacía referencia a un tipo de organización armada integrada por paisanos con el fin de defender la isla ${ }^{4}$. De esta forma se atendia a la defensa del territorio con el fin de suplir la deficiencia de militares convencionales.

Las características de estas milicias vienen marcadas por la vinculación de estas a los Cabildos, quienes desde bien pronto tuvieron que hacer alardes para convocar a los hombres capaces de empuñar un arma en cuanto había una amenaza; por tanto, podemos considerarlas como unidades autónomas, que en cuanto a material contaban con escasos recursos y con poca disciplina ${ }^{5}$, razón por la cual la Corona se vio en la necesidad de enviar presidios para instruir a esta tropa, pues en alguna ocasión y ante cualquier eventual ataque las distintas instituciones se organizaban para la defensa sin tener

\footnotetext{
3 BORREGUERO BELTRÁN, C.: "El ejército del rey", en O`DONNELL, H. (dir.): Historia militar de España. III. Edad Moderna..., Madrid, 2013, p. 126.

${ }^{4}$ CONTRERAS GAY, J.: "Las milicias en el Antiguo Régimen. Modelos, características generales y significado histórico", Chronica Nova, 20, Granada, 1992, pp. 75-103.

5 DARIAS PADRÓN, D.: "Sumaria histórica orgánica de las milicias de Canarias», El Museo Canario, año XII, núms. 37-40, enero-diciembre, 1951, pp. 99-208.
} 
apenas conocimiento de estrategia ni de instrucción militar alguna. Así, por ejemplo, se nos habla de un llamativo acuerdo del Cabildo catedral de Canarias en el que disponía en 1553 que, en caso de que la isla fuera invadida, el deán ejerciera las funciones de capitán y el arcediano las de alférez ${ }^{6}$.

La primera estructura miliciana que se conoce en Gran Canaria, aunque hay quien sostiene que se creó antes, se organizó mediante ordenanzas propias ${ }^{7}$ durante el mandato en la gobernación de la isla de don Rodrigo Manrique de Acuña, nombrado como tal por el Consejo en 1549, y con él se nombró como capitán del rey, a instancias del Cabildo, a Pedro Cerón, con el único fin de encargarse de los asuntos propios dela guerra, que mantiene hasta su fallecimiento, fecha en que el cargo se extingue con su persona8; es a partir de aquí cuando la isla se divide en distritos militares 9 .

A partir de esta fecha fue cuando se puso en marcha la distribución territorial de la isla en compañias, con el nombramiento de capitanes, quedando a partir de entonces de un modo estable, con lo cual ya fueron continuos las llamadas a alardes particulares y generales, con la confección de los listados de la gente ${ }^{10}$, aunque estos resultaron molestos para los miembros de las milicias por tener que abandonar en las convocatorias sus ocupaciones y tareas, aparte de las molestias que les ocasionaba el trasladarse desde los distintos pueblos de la isla a la capital de la isla, Las Palmas.

Los capitanes, a partir de su aparición, eran designados por los Cabildos, y a su vez ellos nombraban a los alféreces, sargentos y cabos de la compañía. Por misiva que envía Cerón al príncipe sabemos que apenas fue nombrado hizo un llamamiento general para que todos los hombres de la isla en edad acudiesen a Las Palmas, siendo la primera vez que se definió el organigrama de las milicias con el nombramiento de capitanes de las distintas compañias, con sus alféreces y todo tipo de oficiales y suboficiales, a la vez que se confeccionó una lista y memoria de toda la gente

que en esta ysla avia, asy de pie como de cavallo, e de las armas que cada uno tenía, e se informó e supo de la defensa desta dicha ysla e de las armas que cada uno les heran nesçesarias e con muy grand diligençia e cuidado; e proveyó de gente e capitanía de cavallo, e a los demás capitanes repartió la gente que en esta ciudad avia. ${ }^{11}$.

De acuerdo con el listado y la memoria que se elaboró en esa fecha, Gran Canaria contaba con un número de hombres capaces de defender la isla en

\footnotetext{
6 VIERA Y CLAVIJO, J. de: Extracto de las Actas del cabildo catedral de Canarias (1514-1791), Transcripción y estudio de Esteban Alemán Ruiz y Alexis Brito González, Las Palmas de Gran Canaria, 2007.

7 PERAZA DE AYALA, J.: "Las ordenanzas militares para Canarias en 1590", Revista de Historia Canaria, XXXII, La Laguna, 1968.

8 RUMEU DE ARMAS, A.: "Don Pedro Cerón, Capitán General de la isla de Gran Canaria", El Museo Canario, 7, 17, Las Palmas de Gran Canaria, 1946, pp. 3-32.

9 RUMEU DE ARMAS, A.: Piraterias y ataques navales contra las Islas Canarias, Madrid, 1947-1950, t. II, primera parte, pp. 536-537.

10 RODRÍGUEZ YANES, J. M.: Defensa, reclutas..., op. cit., vol. I, p. 90. AGS, Diversos de Castilla, leg. 13, f. ${ }^{\circ}$ 57. Carta de Pedro Cerón al príncipe Felipe (15 de junio de 1553).

${ }^{11}$ RODRÍGUEZ YANES, J. M.: Defensa, reclutas..., op. cit., vol. I, p. 95.
} 
torno a los 1.300-1.400, pero con un armamento muy poco favorable ${ }^{12}$. A esta tropa se añade una compañia de caballeria, organizada de acuerdo con los hijosdalgo, no muy numerosa, que les hacía asociarse a la condición propia de la nobleza ${ }^{13}$, a cuyo frente estaba el regidor y alférez mayor de Gran Canaria, Miguel de Muxica, a quien sucede con similar experiencia en las cosas de la guerra su hijo del mismo nombre y apellido ${ }^{14}$, por capitán de toda la jente de a caballo desta dicha isla..., además de ostentar el privilegio de llevar la bandera en las compañias de infantería y el estandarte en la de caballería.

Estas milicias, creadas en la isla, a imitación de las tropas veteranas empezaron poco a poco, por los continuos alardes que se hacian, a adquirir un cierto aire marcial, especialmente a partir de la real cédula de 10 de agosto de 1558 en que se nombraba a don Alonso Pacheco, como primer inspector y visitador de las islas, con competencias e instrucciones precisas para organizar la defensa de las islas, pues tenía que inspeccionar las compañias, establecer fechas para la realización de la instrucción militar, así como revisar el estado del armamento, que más bien era escaso.

Esta tropa, convocada siempre por el Cabildo, se dividía en tercios, imitando siempre lo que acontecía en la península, y lo conformaban cierto número de compañias de infantería. No obstante, según Rumeu de Armas no será hasta la publicación de la Real Cédula de 21 de mayo de 1562 cuando Felipe II mandó organizar, de manera definitiva, en toda España, las milicias con algunos privilegios y preeminencias, cercanas a las que gozaban en Castilla los hijosdalgo. Por tanto, será con la llegada de don Rodrigo Manrique de Acuña a Gran Canaria cuando se conocen unas instrucciones precisas acerca de la reorganización de las milicias, y la consiguiente distribución de armas de fuego y de mano.

Este hecho singular hay que situarlo en el contexto del primer intento de crear un ejército de milicianos, aunque la organización más efectiva y estable según Rumeu de Armas data de 1553. El propio gobernador, Manrique de Acuña, relata en la correspondencia que envía a la Corte las disposiciones que motu proprio habia ${ }^{15}$.

En Gran Canaria la sustitución del gobernador Manrique por Luis Serrano Vigil, que llegó a esa isla en enero de 1553, no solo no supuso un retroceso en la formación de las milicias, sino su consolidación y su organización definitiva $^{16}$.

El sistema de milicias a la postre consistía en dejar a los ciudadanos en tiempo de paz hacer su vida normal, aunque se procuraba instruirlos con

\footnotetext{
12 AGS, Diversos de Castilla, leg. 13, f. ${ }^{\circ} 51$.

13 .RODRÍGUEZ YANES, J. M.: Defensa, reclutas..., op. cit., vol. I, p. 75.

${ }^{14}$ LOBO CABRERA, M., y F. BRUQUETAS DE CASTRO: El ingeniero militar Próspero Casola y Canarias (Escritos, informes y descripciones), Las Palmas de Gran Canaria, 2014, doc. 22, p. 267. Nombramiento realizado por don Luis de la Cueva y Benavides en 13 de julio de 1593.

15 RODRÍGUEZ YANES, J. M.: Defensa, reclutas..., op. cit., vol. I, p. 73

16 AGS, Diversos de Castilla, leg. 13, f. 51.
} 


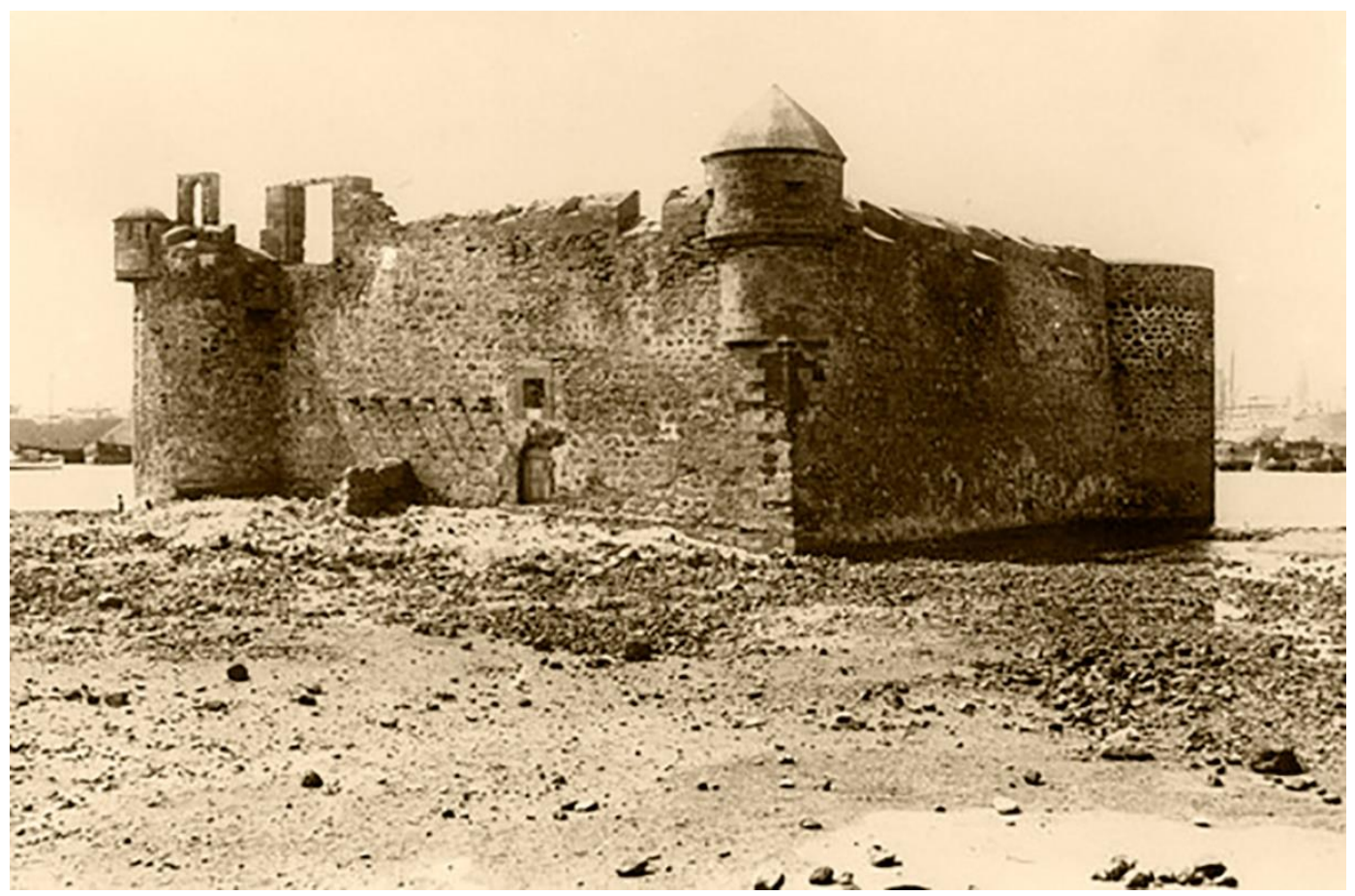

Imagen: Fortaleza de La Luz en Las Palmas de Gran Canaria (fondo Fedac).

cierta asiduidad mediante los alardes para cuando llegase el caso poder utilizar sus servicios. Este tipo de tropa, en Canarias, tuvo que defender durante siglos, sin auxilio de tropas vivas, la defensa de las islas y su propio hogar, sin causar entonces gravamen alguno al real erario pues, como dice Viera, sin duda refiriéndose a los primeros tiempos, el Cabildo - entiéndase Cabildosformaba, disciplinaba y armaba las milicias a sus expensas, a la vez que levantaba y municionaba las fortificaciones y presidía a las expediciones que se hacian contra los moros de las costas occidentales ${ }^{17}$.

Una vez movilizada, la tropa tampoco contaba con un sistema de financiación propio y dependía de la voluntad de los Cabildos, de sus oficiales o de la caridad de los vecinos. Las compañias de infanteria eran las que formaban los tercios y conservaban la referencia de su origen comarcal, mientras la caballería mantenía incluso la forma de compañias sueltas sin llegar a constituir tercio.

Las compañias de artillería prestaban servicio en las torres y castillos que se iban levantando en las islas, al mando de sus respectivos alcaides, nombrados por los Cabildos en las islas mayores, de acuerdo con la autoridad militar.

Cada compañía se agrupaba bajo el mando de un capitán, nombrado por el cabildo realengo. A lo largo del siglo XVI fueron estructurándose jerárquicamente alrededor de un maestre de campo como autoridad superior encargada de marchar con el ejército, alojarlo, disponerlo en la batalla y mantenerlo en justicia. Junto a él va surgiendo toda la oficialidad compuesta por un alférez

17 DARIAS PADRÓN, D. V.: "Sumaria histórica orgánica...", art. cit., pp. 99-208. 
mayor, sargento mayor y coroneles, además de los correspondientes capitanes, alféreces y sargentos de las compañias ${ }^{18}$. Estos últimos estaban a las órdenes de los capitanes con la función específica de enseñar a los miembros de las milicias en estrategia relacionadas con los movimientos, tácticas y escaramuzas $^{19}$.

Esta tropa se dividía en tercios, organizados por el Cabildo, de acuerdo con los gobernadores militares, a imitación de lo que acontecia en la península, con el fin de vigilar y defender la costa, así como guarnicionar las fortalezas. Cada uno estaba formado por un número indeterminado de compañías de infantería, de acuerdo con las comarcas señaladas en la isla, armadas con picas y arcabuces; otra de artillería con algunas piezas de campaña de corto alcance; y una tercera de caballería, formada por la gente más noble y escogida de cada una de las localidades de la isla ${ }^{20}$.

Estas milicias se ejercitaban en días señalados y determinados por el gobernador en el manejo de las armas, como eran las alabardas, chuzos y sables junto con las de fuego, que se repartian entre la población en caso de rebato, aunque los milicianos así registrados se costeaban sus armas, y los miembros de la caballería tenían que aportar su caballo, que en Gran Canaria eran 16 21 , mientras la artillería - cañones, balas y pólvora- corría por cuenta del rey.

Sin embargo, la falta de uniformidad en su composición era la nota característica en la época, pues había tercios desde los 500 hasta los 2.000 soldados, reclutados entre los hombres útiles con edades que iban desde los 15 a los 55-60 años. Para su instrucción y disciplina se creó en cada isla la figura de un sargento mayor, nombrado por el rey y con salario por cuenta de la Real Hacienda, cuya misión consistía en:

...enseñar, yndustriar y ejercitar en el manejo de las armas y en las demás concernientes a la buena disciplina y exercicio de la dicha isla, hasiendo y ejerciendo el oficio de sargento mayor para que ofreciéndose ocasión se hallen diestros y sepan cómo se han de defender $y$ ofender del enemigo, para lo qual tomaréys muestras y alardes a los dichos naturales todas las vezes que al dicho mi governador, a quien avéys de obdebecer, y a bos paresiere convenir y los enseñaréys a ponerse en esquadrón y a escaramusar y las más cosas que según la disposición de la tierra conviniere...

Las milicias, por tanto, eran adiestradas e instruidas por los responsables de las compañias de la ciudad, a la vez que se enviaban instrucciones a los

\footnotetext{
18 DARIAS PADRÓN, D. V.: "Sumaria historia orgánica de las milicias de Canarias", El Museo Canario, ns. 12, 14 y 16, Las Palmas de Gran Canaria, 1951, 1953 y 1955, pp. 99-208, 131204, y 1-37; RUMEU DE ARMAS, A.: Piraterias y ataques navales..., op. cit., t. II, 1. ${ }^{a}$ parte, capitulo III: Las milicias canarias.

19 O`DONNELL Y DUQUE DE ESTRADA, H.: "La táctica y la técnica españolas. El combate en sus diversos tipos", en O`DONNELL, H.: Historia militar de España. III. La Edad Moderna, Madrid, 2013, p. 155.

${ }^{20}$ MILlARES TORRES, A.: Historia general de las Islas Canarias, Las Palmas, edic. de 1977, t. III, pp. 295 y ss.

${ }^{21}$ AGS, Guerra y Marina, leg. 432, f. ${ }^{\circ} 61$.
} 
pueblos del interior para que hicieran lo mismo, y se les debía cursar notificación para que en caso de peligro se concentrasen lo más rápido posible en la plaza mayor de la ciudad ${ }^{22}$.

Los gobernadores, cuando tomaban posesión, una de las primeras cosas que hacian era convocar un alarde para comprobar el estado de las milicias, pues era costumbre a la llegada de un gobernador realizar una inspección y llamamiento general por toda la isla,

...y viene cada lugar con su capitán, vandera, y compañia; salvo que el lugar pequeño se junta con otro, y todos suelen juntarse en la ciudad de Las Palmas, que es la cabeza, donde el gobernador y dos diputados, por ante el escribano del Cabildo, tomaban la lista de la gente, $y$ armas $^{23}$.

Se observa, por tanto, que en aquellos lejanos tiempos la escasa población canaria se armaba en masa para resistir los continuos ataques del exterior, única manera de poderlos entonces rechazar en aquel su aislamiento oceánico. Aquellas masas, poco coherentes y disciplinadas, eran entonces dirigidas y mandadas por un cuerpo eventual de oficiales, reclutado entre la clase hidalga y acomodada, como mandó más tarde Felipe II en la Real Cédula de 30 de Julio de 1583, dirigida a Tomás de Cangas, gobernador de Canaria, en la cual se le previno que los oficios de capitanes y alféreces de las compañias de a cavallo $y$ de pie se proveyesen en personas de valor $y$ experiencia vecinos $y$ naturales jente noble $y$ hacendada ${ }^{24}$.

De hecho, las milicias constituían el único sistema defensivo existente en Canarias y América, cuya misión era acudir a defender la tierra, siguiendo la tradición medieval, con arreglo a sus posibilidades económicas; de ahí que muchos acudieran al alarde con sus caballos o con sus armas como simples peones, tal como aconteció en los distintos ataques que sufrió Gran Canaria, en especial a fines del siglo XVI, cuando fue sorprendida por Francis Drake y Peter van der Does ${ }^{25}$.

\section{Los presidios}

El presidio, aunque tiene distintas acepciones, hay que entenderlo como una guarnición militar destacada en un lugar determinado para defender el territorio, hasta el punto de que el propio Antonio Elio de Nebrija, en su Diccionario latino-español del año 1492, le daba como significado a la palabra presidium el de guarnición.

Este tipo de agrupamiento, formado por soldados profesionales, la mayor parte de las veces veteranos, estuvo presente en Canarias, como apoyo principal a las milicias, desde los momentos de la conquista, pues se considerada como una fuerza vital para custodiar las fronteras y especialmente para evitar los peligros que pudiera ocasionar cualquier ataque pirático, máxime en una

22 RUMEU DE ARMAS, A.: Piraterias..., op. cit., t. II, 2. ${ }^{a}$ parte, pp. 796-797.

${ }^{23}$ CASTILLO DE BOVADILLLA, J.: Política para corregidores y señores de vasallos en tiempos de paz y guerra, Madrid, 1775, p. 441.

${ }^{24}$ RUMEU DE ARMAS, A.: Piraterias y ataques navales..., op. cit., t. II, $1 .^{\text {a }}$ parte, pp. 487-488.

${ }^{25}$ LOBO CABRERA, M.: Alonso Alvarado y Antonio Pamo Chamoso, Madrid, 2017, pp. 43-45. 
isla situada estratégicamente en medio del Atlántico y apetecida por los enemigos de la Corona española.

Estas guarniciones se situaban en los núcleos urbanos, bien en los campamentos militares o en las propias fortalezas existentes en el lugar, aunque en Gran Canaria, dada la poca volumetría de sus defensas, los soldados campaban por la ciudad y sus aledaños.

A lo largo de la centuria solo tenemos referencia a la presencia de soldados veteranos $^{26}$ en dos o tres ocasiones, aunque hay quien aventura que en la propia conquista de Gran Canaria se empleó un presidio para instruir a las fuerzas ofensivas en la empresa militar, mientras que la defensa recaía directamente en las milicias organizadas por el gobernador de la isla.

Los orígenes, al parecer, de las tropas regladas en la isla de Gran Canaria, entendidas como componentes de una guarnición, hay quien los sitúa en una fecha dentro de la conquista de la isla, cuando los Reyes Católicos, por real cédula expedida en Medina del Campo en 24 de noviembre de 1480, envían a la isla para reforzar el presidio a 50 infantes. Según esta noticia, los soldados profesionales tenian la misión de adiestrar a todas aquellas personas que actuaban en la guerra de conquista. De acuerdo con esta información, podemos entender que el real de Las Palmas pudo contar desde poco tiempo después de la finalización del proceso de conquista de Canarias con una guarnición de entre 40 y 60 soldados situados bajo el mando de un sargento mayor, pagados por el real erario, cuya misión principal consistía en mantener la defensa y el orden en la ciudad, además de guarnicionar convenientemente su castillo o presidio $^{27}$.

Sin embargo, según estudios más recientes los historiadores dan como fecha del establecimiento en Las Palmas del más antiguo presidio el año de 1570, fecha de la llegada a la isla de Gran Canaria del primer capitán gobernador, que recaía en la persona de Juan de Benavides.

En 1570 , mientras se llevaban a cabo algunas construcciones y reparos en las defensas, el monarca envia a la isla al ingeniero italiano Agustín Amodeo, acompañado del capitán Gaspar Salcedo con doce soldados de presidio y tres artilleros con la misión de que instruyesen a las milicias, al tiempo que se convertía en un pequeño refuerzo para asegurar la defensa ${ }^{28}$.

Salcedo, como militar profesional, una vez que llega a Gran Canaria mantiene correspondencia con el rey para informarle de la situación en que se encontraba la isla en cuanto a la defensa, de ahí que le exponga no solo lo relativo a las milicias sino también un plan para amurallar la ciudad. En relación con la gente que encuentra en Gran Canaria resaltaba la necesidad de que fuera instruida en el ejercicio militar, algo que ya había comenzado a hacer experimentando una gran mejoría el capítulo de la disciplina militar, el

26 SOLBES FERRI, S.: "La defensa de las Islas Canarias en el siglo XVIII: modificaciones presupuestarias para su financiación", en GONZÁLEZ ENCISO, A (ed.): Un Estado Militar. España, 1650-1820, Actas, Madrid, 2012, pp. 89-121.

27 Ibid., pp. 89-90.

${ }^{28}$ RUMEU DE ARMAS, A.: Piraterias y ataques navales..., op. cit., t. II, primera parte, p. 542. 
qual fruto es tan grande que la gente valería al doble de lo que valia ${ }^{29}$. Sin embargo, más adelante, a final del siglo el gobernador Alonso Alvarado, después de haber comprobado la destreza de los milicianos en la defensa de la isla frente al ataque del corsario Francis Drake opinaba todo lo contrario y así comentaba: ...es jente suelta y que con una lança corta y liviana son muy ágiles, y aqui no an de pelear en esquadrones sino en mangas, porque no es tierra para ello... ${ }^{30}$.

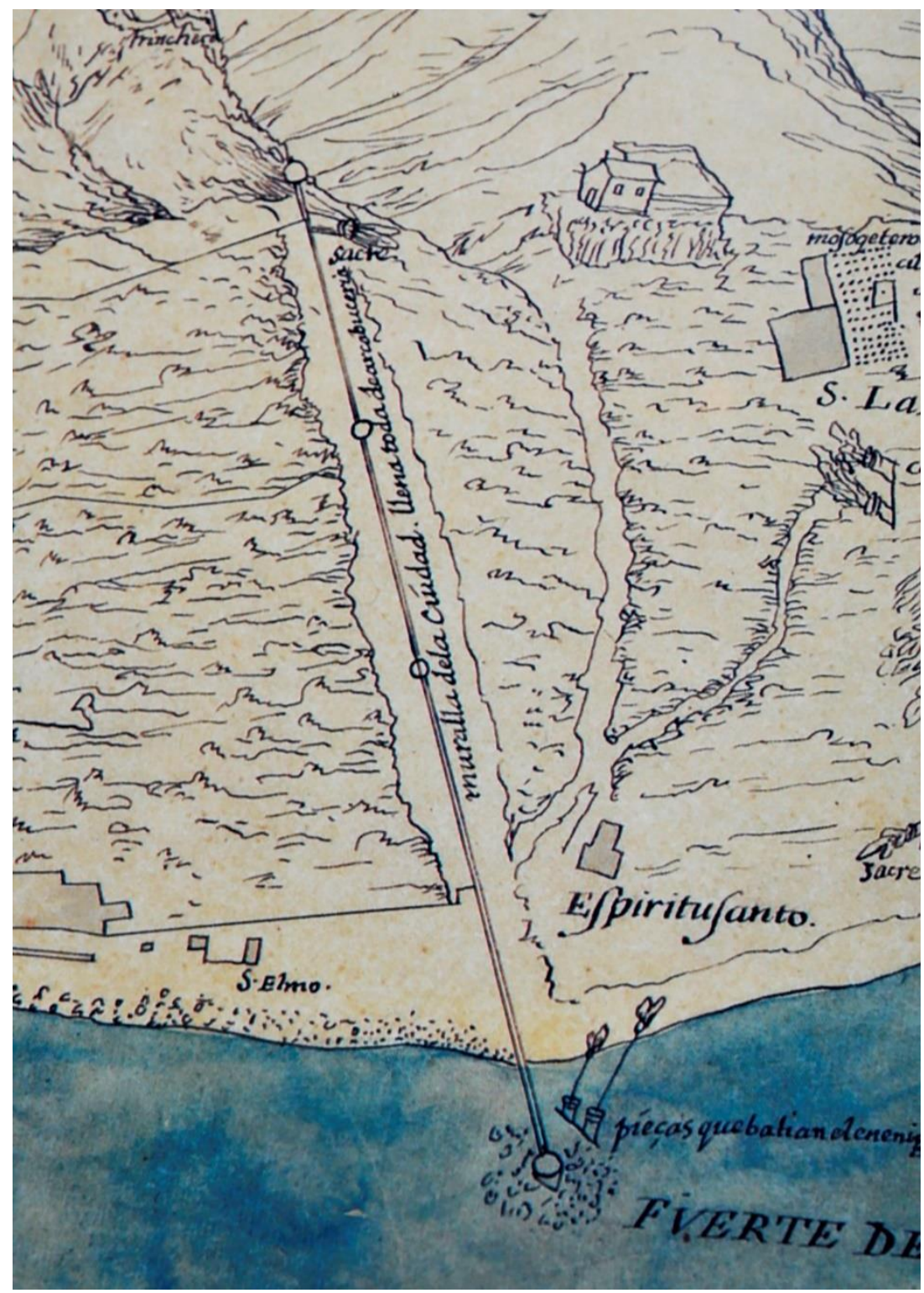

Imagen: Muralla norte de la ciudad y torre de Santa Ana, cerca de San Telmo (fragmento del croquis del ingeniero Casola con motivo del ataque holandés de 1599) [Las Palmas de Gran Canaria a través de la cartografía (1588-1899), textos de Juan Tous Meliá y Alfredo Herrera Piqué, 1995, p. 48]

${ }^{29}$ LOBO CABRERA, M. y F. BRUQUETAS DE CASTRO: El ingeniero militar Próspero Casola..., op. cit., p. 92.

30 AGS, Guerra y Marina, leg. 432, f. ${ }^{\circ} 61$. 
El capitán contaba que antes de llegar él a Canarias todos los isleños solian dormir vestidos y con sus alhajas liadas para que cuando tocasse arma echar a huir a la sierra, y después de su llegada con los soldados del presidio y el armamento que les había regalado el rey se hallaban tan contentos y con tanto ánimo que ya no temían a los enemigos ${ }^{31}$. No obstante, decía, la ciudad tenía mucha necesidad de fortificarse y especialmente el castillo del puerto, el cual debía alzarse tres o cuatro cañas ${ }^{32}$ más de lo que estaba, porque era muy bajo y se hallaba en riesgo de ser asaltado fácilmente con escalas; además de que al ser de tan poca altura no dominaba el puerto y esto era imprescindible para su defensa ${ }^{33}$.

La llegada del capitán Salcedo a Gran Canaria, según este informaba, redundó en una mejora de la instrucción, aunque precisaba que era menester avanzar en ese capítulo para preparar convenientemente a los isleños, razón por la cual obtuvo la facultad para reclutar a 12 soldados prácticos y con experiencia, junto con tres artilleros, con el fin de instruir convenientemente a los canarios tanto en el manejo de las armas como en todo aquello que tuviese que ver con la táctica de defensa y la estrategia. A la vez interesaba al Consejo de la necesidad de muchos hombres, cerca de 2.000, para poder defender las murallas y las fortificaciones ${ }^{34}$.

Este presidio, establecido en Las Palmas, se reforzó con 40 soldados y 3 artilleros, más a raíz del saqueo de Teguise en septiembre de 1571 por Dogalî35; así, en 1572 el presidio se vio aumentado con la incorporación de estos soldados, de acuerdo con la real cédula emitida por Felipe II en donde ordenaba a la Casa de la Contratación la recluta y el envío de los hombres señalados para afianzar con su presencia las milicias insulares, aunque no tenemos indicios de su continuidad en la isla ${ }^{36}$. De esta última partida de 40 soldados, los dos tercios eran piqueros y el resto arcabuceros.

La composición por edad y procedencia era diferente de los elegidos por Salcedo, pues tal como señala Rodríguez Yanes, la mayoría, 22, oscilaban entre 20-25 años, y solo 11 tenían 30 años o más. En cuanto al origen, destacaban con nitidez tres zonas: la actual comunidad de Castilla y León (12 soldados), Andalucía (10) y Extremadura (9), y resulta interesante mencionar en cuarto lugar la filiación portuguesa de cinco. El salario concertado era inferior al del contingente de Salcedo, pues la mensualidad se estableció en 33 reales a los piqueros, 36 a los arcabuceros y 50 a los artilleros ${ }^{37}$.

Posteriormente, en 1580, aunque no se tratase de un presidio en el sentido exacto de la palabra, llegaron a la isla dos instructores ${ }^{38}$, el alférez Juan Niño

\footnotetext{
${ }^{31}$ LOBO CABRERA, M. y F. BRUQUETAS DE CASTRO: El ingeniero militar Próspero Casola..., op. cit., p. 310.

${ }^{32}$ La caña era una medida de longitud basada en la caña de azúcar adulta, cuyo tallo suele medir entre cuatro y cinco metros.

${ }^{33}$ LOBO CABRERA, M. y F. BRUQUETAS DE CASTRO: El ingeniero militar Próspero Casola..., op. cit., p. 92

34 Ibid., p. 312.

35 AGS, Guerra y Marina, leg. 78, f. ${ }^{\circ} 660$.

36 AGS, Guerra y Marina, leg. 76. Orden de 16 de junio de 1572.

${ }^{37}$ RODRÍGUEZ YANES, J. M.: Defensa, reclutas..., op. cit., vol. I, p. 169.

38 RUMEU DE ARMAS, A.: Piraterias y ataques navales..., op. cit., t. II, $1 .^{\text {a }}$ parte, p. 543.
} 
y el sargento José Archidona, con el fin de ejercitar e instruir a las milicias canarias ${ }^{39}$.

\section{El presidio de don Luis de la Cueva}

Después de años sin presidio, Felipe II, entendió en fecha posterior al episodio de la Armada Invencible que para mejorar la defensa de las islas Canarias y reformar la organización político-militar había que darle un giro, centralizando el mando político, militar y judicial en una persona, razón por la cual nombró en 11 de enero de 1589, mediante instrucciones precisas a través de una cédula expedida en 10 de marzo de 1589, como capitán general, gobernador y presidente de la Real Audiencia a don Luis de la Cueva y Benavides $^{40}$. Esta persona reunía en su currículo el ser un buen militar, valiente, activo y con experiencia ${ }^{41}$, además de su categoría de noble, pues vivía en Bedmar como tal señor del lugar.

En la citada orden se recogian las funciones que el capitán general debía asumir, entre ellas la del gobierno conjunto de las milicias en Canarias, entendiendo la forma que tenian los naturales para defender y dar seguridad a las islas, y actuando con orden y disciplina, pues el rey, quizá conocedor de la situación creada en la isla con la tropa le encargaba estudiar la forma de milicia que los naturales tienen entre si para su defensa y seguridad, y pareciéndoos que conviene reformarla, lo haréis tratando con los mismos naturales para que se haga con su beneplácito. El nuevo militar con tan amplias atribu-ciones buscará disminuir la supremacia señorial en las milicias de las islas no realengas.

Para ello trajo consigo un presidio, siguiendo las directrices del Consejo de Guerra, formado por tres compañias de fuerzas veteranas, parte de las cuales se retirarian en 1594 junto con don Luis de la Cueva, dejando en las islas una guarnición, distribuida entre Gran Canaria, Tenerife y La Palma. Le acompañaban sus hijos Alonso de la Cueva y Benavides, nacido en 1577, señor de Solera, Jaén, el cual siguió la carrera de las armas apoyado por su padre, donde prestó grandes servicios a la Corona, junto con Luis y Juan, este último alférez de la compañia de Juan Jaraquemada, y luego capitán de la compañia que mandaba Juan Fernández de Viedma, por fallecimiento de este.

También vino consigo un presidio compuesto por 600 soldados veteranos, de cuya experiencia militar confiaba el rey la seguridad del archipiélago ${ }^{42}$. Fueron primero alojados en Sevilla, para desde alli embarcar en la flota de Indias, lo que retrasó su llegada, al surgir en Gran Canaria el 18 de julio de 1589. A esas alturas, los 500 soldados en dos compañias se habían convertido en 600 en tres compañias, cuyo sueldo supondría cerca de 3.000 ducados mensuales, mientras el salario de don Luis ascendía a 2.000 ducados anuales, aparte de los alabarderos (unos 600 ducados anuales, ya que 11 percibían 4

39 Ibid., p. 518.

40 ÁLAMO MARTEL, M. D.: El capitán General de Canarias en el siglo XVIII, Las Palmas de Gran Canaria, 2000, pp. 23-28.

${ }^{41}$ RUMEU DE ARMAS, A.: Piraterias y ataques navales..., op. cit., t. II, segunda parte, p. 560.

42 Ibid., p. 564. 
ducados mensuales, y su cabo 6 ducados) ${ }^{43}$. No obstante, la travesía de la expedición que acompañaba al general fue corta (unos pocos días desde la bahía del puerto de Santa Maria, Cádiz, a Gran Canaria).

Los soldados llegaron armados de morrión, coselete, y distribuidos en tres compañias de mosqueteros, arcabuceros y piqueros, mandados por los capitanes Juan Fernández de Viedma, Gaspar Fernández de Ayala y Juan Jaraquemada, este último natural de Telde y caballero de la orden de Santiago ${ }^{44}$, nombrado visitador para todas las islas, aunque luego, durante la estancia del presidio en el archipiélago, se produjeron cambios.

Además, en el sequito del capitán general figuraban sus hijos, el ingeniero Próspero Casola, y los posteriores nombramientos del veedor y contador de la gente de guerra Juan del Hoyo, el pagador Gaspar de Ayala, nombrado expresamente por una cédula real, y el oficial Martín de Achivite ${ }^{45}$, más 8 artilleros con el cabo Juan Negrete, al frente, y como auxiliar polvorista Alonso de Valenzuela ${ }^{46}$. En efecto, Gaspar de Ayala fue nombrado como tal pagador el 8 de octubre de 1590 con la encomienda de distribuir el dinero que llegase a sus manos entre las fortificaciones, compra de armas, bastimentos, materiales y el sueldo de la gente de guerra, con la intervención del veedor y las órdenes y libranzas del capitán general ${ }^{47}$. En efecto, como tal oficial debía tener un libro donde debía constar el dinero que recibía de las rentas reales de las islas para el pago de los sueldos de la gente de guerra; otro con las listas, pagas y socorros; y otro con las nóminas y libranzas despachadas por el veedor, tocante al sueldo de la gente de guerra ${ }^{48}$, el cual había comenzado en 1594 y contenía setenta y tres pliegos.

El capitán general tenía como función el mantenimiento del presidio militar a toda costa, para conseguir el más absoluto centralismo en materia militar, además de otras obligaciones para el cumplimiento de la defensa.

A su llegada se hizo alarde general, concurriendo en la plaza mayor de Santa Ana todos los tercios de milicias con sus banderas y oficiales, que fueron revistados por don Luis de la Cueva, después de que el sargento mayor Jerónimo de Aguilera, que había llegado a la isla con don Luis de la Cueva, revisara las milicias e hiciera maniobrar a las distintas compañias que habian llegado a la ciudad desde distintos puntos de la geografia insular. A su vez, programó una visita general por todas las islas, dejando al mando del presidio en Las Palmas a su hijo Alonso.

La etapa del capitán general en Canarias fue bastante polémica, pues introdujo innovaciones militares con un tono de soberbia y autoritarismo hasta la fecha no conocido, de ahí su confrontación con las autoridades locales. El pri-

\footnotetext{
${ }^{43}$ AGS, Consejo y Junta de Hacienda, leg. 270, f. ${ }^{\circ} 16$.

${ }^{44}$ RUMEU DE ARMAS, A.: Piraterias y ataques navales..., op. cit., t. II, segunda parte, pp. 565-566.

45 Archivo Municipal de Santa Cruz de La Palma, Reales Cédulas.

46 RUMEU DE ARMAS, A.: Piraterías y ataques navales..., op. cit., t. II, segunda parte, pp. 566-567.

${ }^{47}$ LOBO CABRERA, M., y F. BRUQUETAS DE CASTRO: El ingeniero militar Próspero Casola..., op. cit., doc. 16, pp. 254-255.

48 Ibid., doc. 101, p. 436.
} 
mer choque se produjo por las cuestiones relacionadas con el alojamiento de los soldados del presidio, que fue repartido en principio entre las islas (50 a Tenerife), aunque Gran Canaria estimaba que ella sola no podia soportar el peso de dar hospedaje a todo el presidio y solicitaba se trasladaran a Tenerife 200, pues ya el capitán general le había obligado a desalojar 850 ducados anuales para los gastos del aposentamiento de la tropa ${ }^{49}$, que fue ampliado a 300 para agilizar los gastos que tenía que soportar Gran Canaria, gracias a la real cédula obtenida por esta isla del Consejo de Guerra el 28 de octubre de $1591^{50}$.

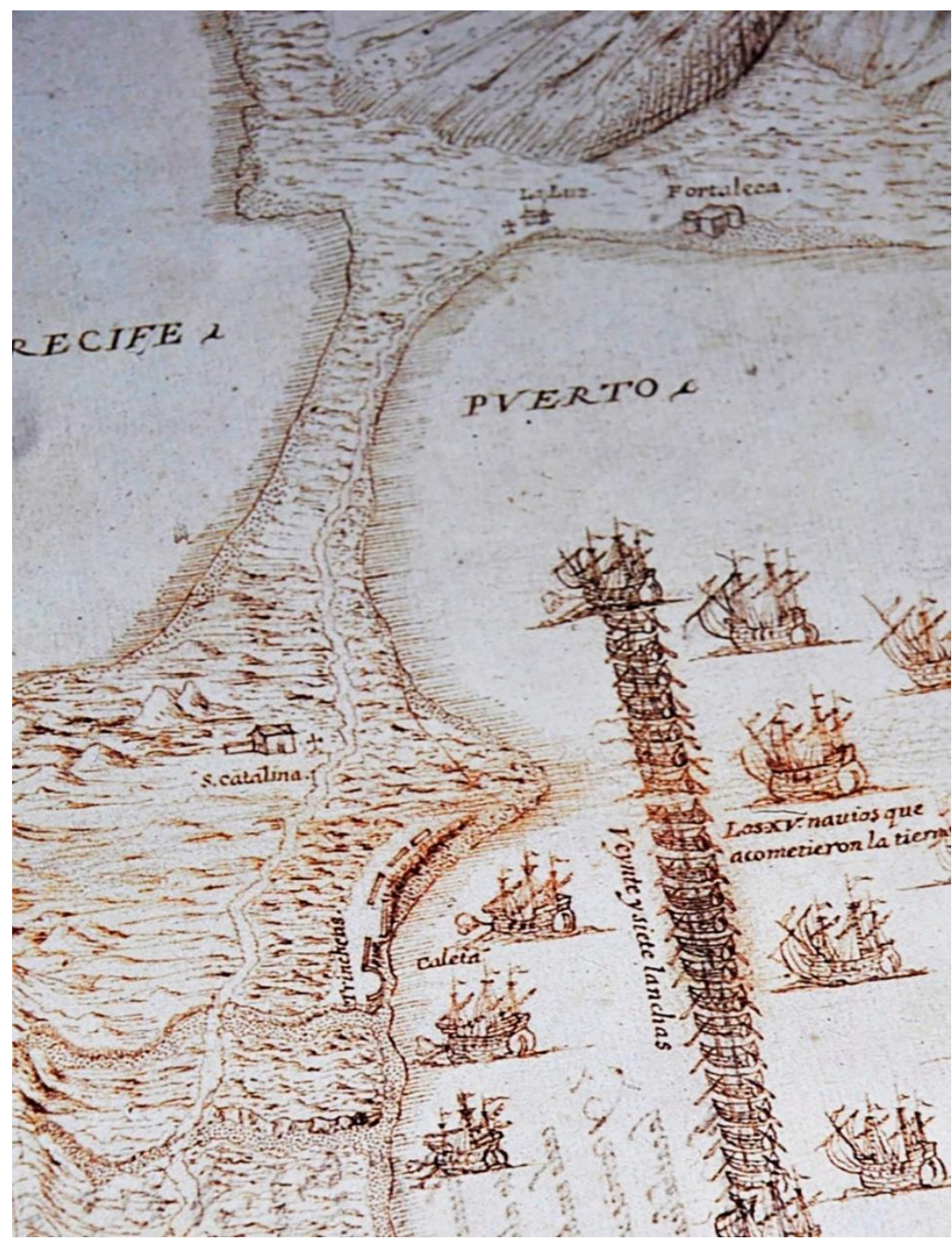

Imagen: Fragmento del croquis representando el ataque de Drake a Las Palmas de Gran Canaria en 1595. Se observan las trincheras en la costa frente a la flota invasora. A la derecha, en la Isleta, la fortaleza de La Luz [Las Palmas de Gran Canaria a través de la cartografía..., op. cit., p. 48].

49 Archivo Municipal de La Laguna, Libro de Acuerdos, sesión de 3 de agosto de 1590.

50 RUMEU DE ARMAS, A.: Piraterias y ataques navales..., op. cit., t. II, segunda parte, p. 576. 
En Las Palmas quedó una compañia, dividida en dos, bajo el mando de Juan Fernández de Viedma y Luis de Benavides, aunque en marzo de 1592 cambió su política y acuarteló todo el presidio en Las Palmas, con la obligación de que todas las islas contribuyesen a su mantenimiento, con el fin de acudir desde allí adonde fuere necesario.

En Gran Canaria, siguiendo las directrices de las instrucciones reales, alteró la organización castrense establecida. Hubo supresión de tercios en la capital y en la zona norte de la isla; conservación de un tercio, al mando de un cabo, en la zona sur de la isla, donde se agrupaban las compañias de Telde y Agüimes, y puesta en su total orden a todo el ejército insular. De tal manera, que de acuerdo con esta reestructuración Las Palmas contaría con cuatro compañias de infantería y una de caballería; por el centro y norte de la isla se repartian cinco más, que comprendian a las milicias de La Vega, Teror, Arucas, Guía y Gáldar; y por el sur cuatro, a saber: dos en Telde y dos en Agüimes, mandadas por un cabo ${ }^{51}$.

Los habitantes de Las Palmas y de toda Gran Canaria quedaban obligados a alojar a los soldados, dándoles colchón, cama, mesa, almohada y limpieza de ropa cada 8 dias en verano y cada quince en invierno. Las demás islas tenían que contribuir por cada boca de soldado con 8 reales al mes.

Los problemas surgidos entre los Cabildos y el capitán general acerca del alojamiento de los soldados del presidio, además de los tira y afloja y los conflictos creados entre don Luis de la Cueva y las autoridades locales, ocasionaron que el 20 de septiembre de1592, mediante una real provisión, se le ordenara al capitán general el embarque con destino a la península, a sus cuarteles de origen, de la mitad de las tropas del presidio, de tal modo que el 4 de octubre de 1593 solo quedaban concentrados en Gran Canaria unos 240 soldados del presidio ${ }^{52}$.

\section{El ataque de Xabán Arráez}

Los problemas que tuvo el capitán general durante su estancia en Canarias entre 1589 y 1594 se agravaron con el desastre sufrido en la expedición enviada a Fuerteventura, con ocasión del ataque e invasión que llevaron adelante las huestes de Xabán Arráez en agosto de 1593.

Habrá que convenir que, más que una victoria de los berberiscos, el episodio de Fuerteventura fue obra de los propios soldados del presidio enviados por el capitán general, de tal modo que fueron el caos y la cobardía los protagonistas de la derrota ${ }^{53}$.

El 12 de agosto de 1593 se tenía noticia en Gran Canaria de la llegada de moros a las costas del archipiélago con una flota de siete embarcaciones, que fue confirmada dos dias más tarde por una barca que desde Fuerteventura llegaba con el aviso de que los moros habian invadido la isla. Don Luis tomó

51 Ibid., p. 596

52 RUMEU DE ARMAS, A.: Piraterías y ataques navales..., op. cit., t. II, segunda parte, pp. 580-581. AGS, Guerra y Marina, leg. 383.

53 AGS, Diversos de Castilla, leg. 13, f. ${ }^{\circ}$ 56. Carta de 30 de octubre de 1593 de Tomás de Cangas al rey. 
la decisión de socorrer Fuerteventura después de adiestrar a los capitanes que iban al frente de los soldados, junto con algunos miembros de las milicias, más prácticos y conocedores de la tierra; sin embargo, la preparación de la expedición se dilató en el tiempo, quizá por la falta de embarcaciones que ya hacía tiempo que se venía notando en Gran Canaria por la actividad mercantil que mantenía con el resto de las islas y con las Indias, y por el empeño en seleccionar a los mejores soldados. Al parecer, fueron enviados a la defensa y socorro de Fuerteventura unos 240 soldados, entre veteranos y milicianos, mosqueteros y arcabuceros ${ }^{54}$, con sus jefes al mando, instruidos por el capitán general sobre la táctica a seguir, quienes, a su vez, iban bajo las órdenes de Juan Xaraquemada, aleccionado por D. Luis de la Cueva en ese sentido.

Algunos de los soldados que participaron en esta operación, contagiados por el temor que circulaba por la isla sobre los ataques perpetrados por los berberiscos en las islas de Lanzarote y Fuerteventura, otorgaron su última voluntad antes de partir, y entre ellos podemos citar a varios. Entre el 16 de agosto y el 1 de septiembre de 1593 testaron Sebastián de la Raya, Alonso Pérez, el soldado Lara y Bartolomé Montoro, todos andaluces: uno de Sabrote, otro de Lucena, el tercero de Guadix y el último de Bujalance. Todos confiesan que hacen su testamento por estar de partida para la isla de Fuerteventura, por mandado de don Luis de la Cueva, al socorro de dicha isla, porque la estaban saqueando los moros y turcos enemigos de la santa fe católica. De los cuatro, uno era arcabucero y cabo de escuadra. Dos de ellos se declaran miembros de la compañia de don Juan Xaraquemada, mientras los otros dos señalan formar parte de la compañia del capitán de infantería don Luis Robres y Benavides y de la del capitán don Luis de Benavides, hijo del capitán general.

Todos, en el momento de otorgar dicha escritura, son solteros, buenos cristianos y pobres, pues apenas tenían bienes, salvo sus ropas de vestir, y llenos de deudas porque no habían recibido las pagas correspondientes a sus servicios, razón por la cual encargan a sus albaceas que las pongan en orden con el contador Juan del Hoyo, para que puedan hacer cumplir las mandas de su testamento, casi todas religiosas, para ordenar sus misas y funerales ${ }^{55}$.

Esta operación puede catalogarse como la primera de carácter militar en donde los veteranos del presidio podian dar pruebas de su profesionalidad. Llegaron a Fuerteventura el día 19 de agosto, cinco dias después de haberse producido el asalto e invasión. Los soldados, una vez desembarcados, algo mareados, pues la travesía no había sido fácil, apenas habian caminado unas dos leguas en el camino hacia Betancuria cuando acometieron de manera precipitada a un grupo de 20 moros que estaban cogiendo ganado en el lugar conocido como Siete Fuentes, hoy Los Canarios. Esta actitud se convirtió en el desencadenante de la derrota de los soldados, pues en respuesta a tal acometida unos 200 moros hicieron que se descompusieran y huyeran en dirección hacia donde estaba el resto de la tropa, que en vez de reorganizarse para acometer a los berberiscos, se contagió del pánico y abandonó las armas al

54 AGS, Guerra y Marina, leg. 280, f. ${ }^{\circ} 49$.

55 Archivo Histórico Provincial de Las Palmas (AHPLP), Teodoro Calderín, leg. n. ${ }^{\circ}$ 900, testamento de Sebastián de la Raya, f. ${ }^{\circ} 388$ r.; testamento de Alonso de Lara, f. ${ }^{\circ} 423$ v.; testamento de Alonso Pérez, f. ${ }^{\circ} 431$ r.; y testamento de Bartolomé Montoro f. ${ }^{\circ} 433$ v. 
enemigo ${ }^{56}$, con el resultado de unos 30 muertos, para reembarcarse con destino a Gran Canaria ${ }^{57}$. Aunque los berberiscos habian hecho cautivos a muchos vecinos de la isla, según los historiadores hasta sesenta, los soldados de don Luis de la Cueva cautivaron también a algunos moros en su huida, tal como declara en 1594 Alonso de Bustamante. Este nos dice que se había hecho mucho gasto en mantener a los moros que habian apresado en Fuerteventura, los cuales habian venido con Xabán Arráez, y se habian llevado a Gran Canaria, algunos de los cuales se habian vendido como esclavos ${ }^{58}$.

Este hecho no hizo más que acrecentar el descredito del presidio, razón por la que el rey ordenó en noviembre de 1593 su retorno a la península mediante carta en donde se le hace el nombramiento como oficial real para incorporarse a Galicia ${ }^{59}$. En efecto, aunque el nuevo nombramiento se había efectuado con anterioridad, el 11 de enero de 1594, se embarcaron unos 200 hombres en compañía de don Luis de la Cueva ${ }^{60}$, quedando del antiguo presidio 40 soldados en Gran Canaria, aun cuando en los libros de la veeduría constaba que eran 4461, con el cabo Alonso de Aguilera Valdivia y el cabo de escuadra Antón Chiquero62. También quedaron en Gran Canaria el veedor y contador Juan del Hoyo, el pagador Gaspar de Ayala, el ingeniero Próspero Casola, el cabo de artillería Juan Negrete y el polvorista Alonso de Valenzuela, cuyo costo suponía para la Corona 897.600 maravedís ${ }^{63}$. No obstante, según escrito remitido al rey por Gaspar de Ayala, como antiguo pagador de la gente de guerra, ahora como regidor de Gran Canaria, habian quedado en las islas 52 soldados, un cabo para guardar las fortalezas, con 12 más que estaban en La Palma, más un cabo de artillero y otros oficiales, los cuales todavía en 1595 pasaban bastante necesidad porque no se les pagaba su sueldo por el pagador por tener expresa orden al haber muerto el contador y veedor Juan del Hoyo, quien había fallecido en 11 de marzo de $1595^{64}$, razón por la cual en previsión del nuevo nombramiento se propone a Martín Chivite 65 . Finalmente es nombrado Ruy Díaz de Rojas Manrique en sustitución del difunto Hoyo, a quien se le manda que tome razón para hacer efectivo el pago a los soldados ${ }^{66}$.

\footnotetext{
56 AGS, Guerra y Marina, leg. 280, f. ${ }^{\circ} 49$.

57 RUMEU DE ARMAS, A.: Piraterias y ataques navales..., op. cit., t. II, segunda parte, p. 639.

58 AHPLP, Francisco Suárez, n. ${ }^{\circ}$ 905, s. f.

59 LOBO CABRERA, M. y F. BRUQUETAS DE CASTRO: El ingeniero militar Próspero Casola..., op. cit., doc. 21, p. 266.

60 RUMEU DE ARMAS, A.: Piraterias y ataques navales..., op. cit., t. II, segunda parte, p. 641.

${ }^{61}$ LOBO CABRERA, M. y F. BRUQUETAS DE CASTRO: El ingeniero militar Próspero Casola..., op. cit., doc. 101, p. 437.

${ }^{62}$ AGS, Guerra y Marina, leg. 444, f. ${ }^{\circ}$ 269. Este se quejaba al rey por haber sido cesado de su puesto por el regente de la Audiencia para dársela a otra persona.

63 AGS, Guerra y Marina, leg. 488. "Relación de lo que monta el sueldo de los oficiales y soldados que en esta isla de Canaria y en la de La Palma quedaron sirviendo a su majestad..... ${ }^{64}$ AGS, Guerra y Marina, leg. 427, f. ${ }^{\circ} 77$.

65 AGS, Guerra y Marina, leg. 432, f. ${ }^{\circ}$ 57. Propuesta hecha por el licenciado Jerónimo de la Milla en 2 de julio de 1595.

${ }^{66}$ AGS, Guerra y Marina, leg. 444, f. ${ }^{\circ}$ 148. De Canaria, 27 de noviembre de 1595.
} 


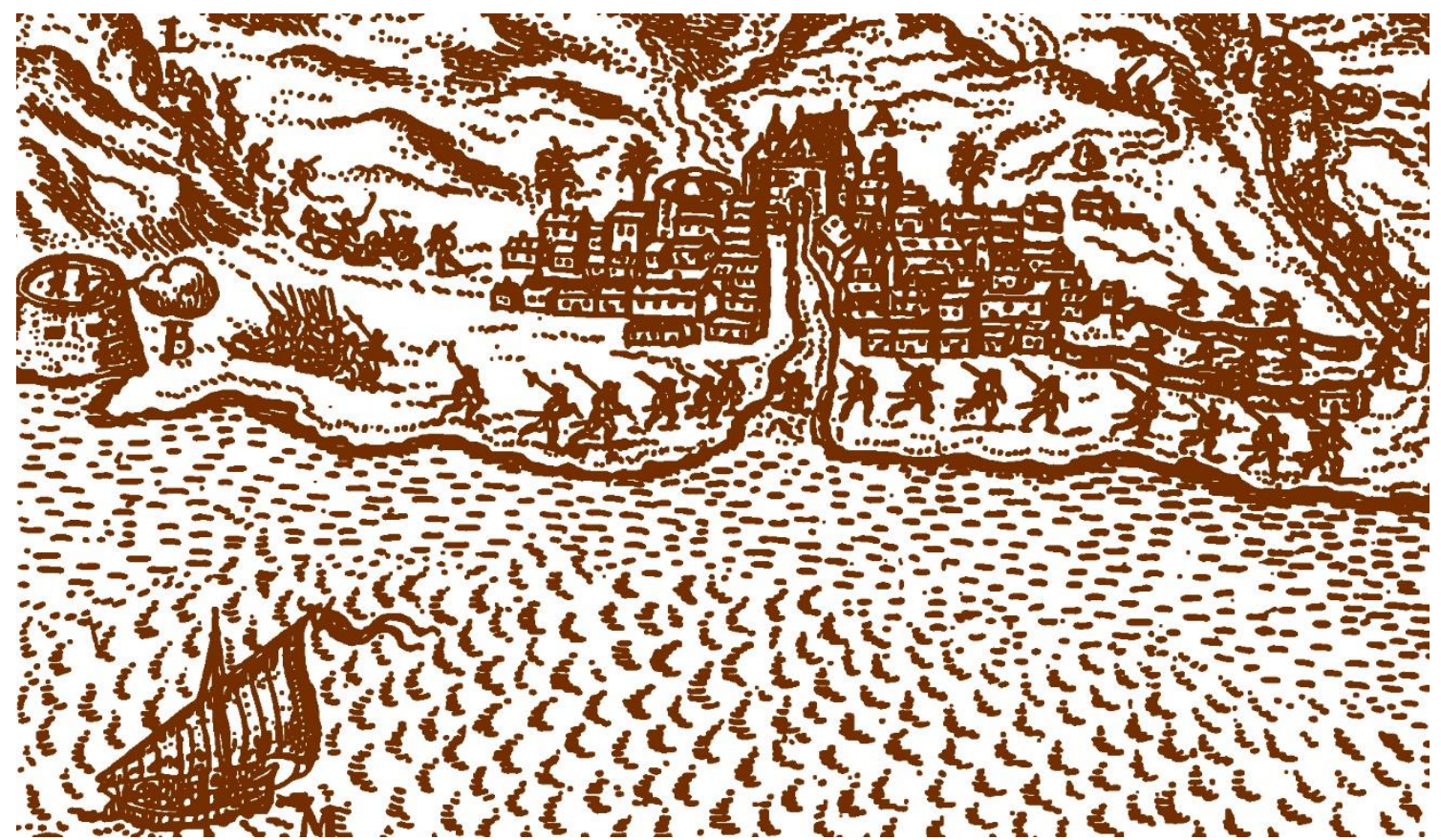

Imagen: Movimiento de tropas en Las Palmas con ocasión de la toma de la ciudad por Van der Does en 1599 (Grabado de De Bry) [Las Palmas de Gran Canaria a través de la cartografía..., op. cit., p. 57].

La nómina del coste de esta unidad dejada en las islas por don Luis de la Cueva ascendia, según una relación anual del sueldo de los oficiales y soldados recogida el 16 de octubre de 1595, a 1.327.258 maravedís, los cuales se distribuian de la siguiente manera: 182.500 maravedís a Juan del Hoyo por su oficio; más 58.752, 93.750 a Gaspar de Ayala, pagador de la gente de guerra; a Juan Negrete, artillero 53.856; a Antonio de Valenzuela, polvorista, 24.480 maravedís; a los 40 soldados arcabuceros, entre ellos un cabo de escuadra y otro para gobierno de ella, que por todos hacían 41, se les señaló de sueldo a razón de 8 escudos de a 10 reales al mes, y al cabo otros 6 escudos. Montaba el sueldo de todos cada año 693.600 maravedís. Los 12 soldados arcabuceros de la isla de La Palma, entre ellos un cabo de escuadra, 204.000 maravedís 67 .

El 12 de octubre el nuevo gobernador Alonso de Alvarado y Ulloa se quejaba al rey de que hasta aquella fecha los soldados no habian cobrado su sueldo, por lo cual, motu proprio, de las rentas reales iba tomando el dinero que era menester para cumplir con los servidores del servicio de guerra, pues entendía que estos sufrian mucho y no se podian sustentar por ser el sueldo corto y la tierra cara ${ }^{68}$.

\section{Los soldados}

67 AGS, Guerra y Marina, leg. 432, f. ${ }^{\circ}$ 62. "Relaçión de lo que monta cada año el sueldo de los oficiales y soldados que en esta isla de Canaria y en la de La Palma quedaron sirviendo a su magestad por su rreal orden desde onze de enero del año pasado de quinientos y noventa y quatro que salió desta isla para yr a España don Luis de la Cueva y de Benavides, gobernador que fue de las dichas yslas con la mayor parte de la gente de guerra que en ella estuvo de guarnición".

68 AGS, Guerra y Marina, leg. 432, f. ${ }^{\circ} 61$. 
Las fuerzas del presidio, una vez llegadas a Gran Canaria, se convirtieron en un perenne elemento de discordia por los continuos roces que propiciaban entre la población, al estar inactivos en aquellos años. A ello se une los primeros choques que se dieron con las autoridades insulares a cuenta de los soldados.

Dos cuestiones se planteaban al respecto: por un lado, el abultado número de personas que llegaban a la isla, con una población que apenas superaba los 12.000 habitantes, a las cuales había que darles manutención y casa; por otro, el problema que generaba la financiación del presidio, que recaía con mayor peso en las islas realengas, entre ellas Gran Canaria. No hay que olvidar que al final desembarcaron en la isla 600 soldados, divididos en tres compañias: dos de arcabuceros, que tenían como responsables a un capitán, un alférez, un sargento, un capellán, dos atambores, un abanderado, un barbero, furriel y 200 soldados, más 8 cabos, 20 mosqueteros y 172 arcabuceros; otra unidad, conformada por un capitán, un alférez, un sargento, un capellán, dos atambores, un pifano, un abanderado, un barbero, un furriel y 200 soldados, de los cuales 61 eran arqueros, 61 coseletes, 20 mosqueteros y 50 picas ${ }^{69}$.

Los capitanes de estas compañias eran, como ya se ha dicho: Alonso de la Cueva y Benavides, hijo del capitán general; Juan Fernández de Viedma, que murió en la isla; Juan Xaraquemada, natural y vecino de Telde. Estos fueron los que vinieron al frente de aquellas desde la península, pero en el transcurso de su estancia en Canaria ocuparon también plaza como capitanes Luis de Robres y Benavides, capitán de infantería, así como Luis de Benavides, Gonzalo Fernández y Gaspar Fernández, capitán de una de las compañias de arcabuceros, por fallecimiento en la isla de Fernández Viedma ${ }^{70}$.

En el mando acompañaron a don Alonso de la Cueva y Benavides como alféreces Luis de Robres y su hermano Luis de Benavides, que en el transcurso de su estancia en Gran Canaria ascendió a capitán. El sargento de dicha compañía fue Juan de Medina, y como cabos de escuadra estuvieron Gonzalo de Herrera y Juan de Arévalo. Finalmente, figuraba como capellán en la compañia Francisco de Navarrete. De la compañia de Juan Fernández de Viedma conocemos al capellán, cuyo nombre era Francisco de Acosta Flores. La compañia del capitán Juan de Jaraquemada tenía entre sus componentes dos cabos de escuadra, que eran Diego Hernández y Alonso de Lara.

Junto a ellos también figuraron como cabos de escuadra Diego Hernández, Juan de Osuna y Miguel de Navidad, y como sargentos mayores Pedro de Matos, un tal Polo y don Antonio de Heredia. Este, en 1598, seguía en Gran Canaria, pues en noviembre de ese año daba poder a su hermano Cristóbal de Heredia, para que en la Corte, hacia donde se encaminaba, solicitara en su nombre cualquier oficio y cargo que el rey fuera servido de hacerle merced, lo que hace pensar en su deseo de retornar a la península, aunque se había casado en la isla con la hija del regidor Sancho Martín de Cubas, a quien le

${ }^{69}$ AGS, Guerra y Marina, leg. 287, f. ${ }^{\circ} 301$.

70 Esta información se recoge a través de los soldados que van otorgando su última voluntad en Las Palmas, casi desde el momento que llegan hasta su marcha definitiva, aun cuando quedó en Gran Canaria un grupo de ellos. 
reclamaba parte de la dote que le había prometido en su casamiento con doña Ana de Cubas, su mujer ${ }^{71}$.

Además, formaban parte del presidio los artilleros Diego Ternero, que estaba radicado en la isla desde la época de don Martín de Benavides, y Juan Negrete, como cabo de artilleros, que ambos quedaron en la isla, jugando un papel destacado en la defensa contra los ataques de Drake y Van der Does en 1595 y 159972 . Juan Negrete tuvo entre sus obligaciones componer una relación de toda la artillería existente en los castillos y fortalezas de las islas ${ }^{73}$.

La importancia de la presencia de artilleros en las islas para apoyar a la fuerza de defensa se corrobora con la real cédula emitida por Felipe II en El Pardo el 7 de mayo de 1590, donde por la falta que habia de oficiales prácticos en Gran Canaria se considera que para remediar tal situación el rey mandaba al capitán general que hiciese un terrero, en lugar cómodo, para que los naturales pudiesen acudir a tirar y ejercitarse en dicho arte, señalándoles para ello una pieza pequeña de bronce. Asistiría a las prácticas el cabo artillero, que actuaría como maestro para habilitar en los días festivos a los naturales que acudieran con voluntad, para que pudieran así servir en la artillería en las ocasiones que se ofrecieran, gozando para ello de las preeminencias que gozaban los artilleros que servian en las fronteras de España ${ }^{74}$.

A esta nómina se añadian Gaspar de Ayala, pagador de la gente de guerra y obras, y Juan del Hoyo, veedor y contador, quien a su muerte fue sustituido por Martín Chivite. Ayala se mantuvo en su puesto, al menos, hasta 1596, fecha en que como tal pagador de la gente de guerra y obras de la isla, y también regidor, confesó haber recibido de Sebastián Díaz, por Alonso de la Guerra, vecino de Tenerife y administrador de las rentas reales, 1.936 reales para la paga del sueldo del cabo y 40 soldados, y de Juan Negrete, cabo de los artilleros 75 .

Estos soldados veteranos fueron enrolados en los momentos siguientes al nombramiento de don Luis como capitán general, pues en el propio momento que el Consejo de Guerra establecía la salida de la península del presidio con 500 hombres, tal lo declara Cristóbal de Baena, que atestigua que había entrado en la compañía de Alonso de Cueva y Benavides, hijo del capitán general, desde que partieron de España ${ }^{76}$. Estos seguramente fueron incorporados por el propio don Luis con la ayuda de sus hijos, pues muchos de los que se engancharon, en los momentos casi inmediatos al nombramiento de don Luis, eran andaluces, pero más específicamente de Jaén y de las zonas cercanas a

${ }^{71}$ AHPLP, Francisco de Hinojosa, n. ${ }^{\circ}$ 967, fols. 195 v. y 198 r.

72 LOBO CABRERA, M.: Alonso de Alvarado..., op. cit.

73 AGS, Guerra y Marina, leg. 345. "Memoria de las fortalezas, artilleros y piezas de artillería que hay en las islas de Canaria..." (año 1591).

${ }^{74}$ Se incluía entre ellas que tirara con arcabuz en la caza y que se no le asignase gente de guerra en sus casas ni tuvieran obligación de hacer guarda ni centinela (LOBO CABRERA, M. y F. BRUQUETAS DE CASTRO: El ingeniero militar Próspero Casola ..., op. cit., doc. 15, p. 253). 75 AHPLP, Francisco Suárez, leg. n. ${ }^{\circ}$ 907, fols. 335 r y 410 r. Dicha cantidad se pagó por un auto de la Audiencia que confirmaba otro auto del gobernador Alonso de Alvarado, quien había proveído 2.000 reales para la paga de los soldados. Esta cantidad se le dio con intervención de Martín Chivite que, por muerte de Juan del Hoyo, era en esa fecha el veedor y contador. 76 AHPLP, Ambrosio de Campos, leg. n. ${ }^{\circ}$ 930, f. ${ }^{\circ} 32$ v. 
Bedmar, lugar de residencia del general. Así tenemos a algunos naturales de Jaén, Martos, Úbeda, Baeza, Arjona, Andújar, que según sus declaraciones señalan como fecha de su enrolamiento el 24 de mayo de 1589. Curiosamente uno, natural de la Torre de Pedro Gil, como otros, cambió su nombre para no ser conocido y así evitar que su familia lo retuviese. Así dijo

...que por cuanto él habia otorgado testamento ante el presente escribano, en el cual se puso su nombre propio como Pero de la Raya, y porque al tiempo que entró por soldado en la dicha compañía se mudó el nombre y se puso Luis de Carmona, lo cual hizo por justas causas e impedimentos que le movieron a ello, y entre ellos fue el no querer ser conocido de parientes porque salió de su tierra contra su voluntad y no quería que se supieses del hasta tanto que Dios le dejase volver 77 .

A ellos se unieron otros veteranos de las provincias de Córdoba y Granada, aunque tampoco faltaron algunos castellanos, de Madrid y Ávila, así como algunos gallegos y extremeños. En su mayoría apenas sabían firmar, tal como lo reconocen en las escrituras que otorgan.

Algunos de los que llegan, bien por el cambio de clima como por las precarias condiciones de vida, enfermaron y fueron alojados en el hospital de San Martín, ordenando por tanto desde alli sus testamentos para el fin de sus días, y dejando incluso por heredera a tal institución ${ }^{78}$.

En cuanto a su estado, por la muestra que tenemos de los testamentos, eran en su mayoría solteros y pobres, dependiendo su vida del sueldo prometido durante su estancia en Canarias, de ahí que casi todos tuvieran deudas con otros compañeros e incluso con los vecinos. Sus pocas pertenencias en muchos casos les sirvieron de sostén para conseguir algunos reales, hipotecándolas y vendiéndolas a los vecinos. La pobreza y la falta de familia, en muchos de ellos, les hace dejar como heredera a su alma.

El atraso en el pago de sus haberes los obligaba a solicitar préstamos, pues en algún caso estuvieron sin cobrar más de dos años ${ }^{79}$, y cuando no, se les pagaba a cuenta en ropas. Alguno confiesa incluso haber recibido un corte de un jubón de Holanda sin forro ${ }^{80}$ y socorros ordinarios como pan, según se contemplaba en los libros del veedor y contador. A ello se añadían otros problemas, como el intento que hubo de cobrarles los derechos de almojarifazgo, según un pliego despachado por el Consejo de Hacienda, razón por la cual el propio capitán general se dirigió al rey para que se les exonerara de tal impuesto, pues en ninguna parte se les exigia tal cargo, igual que acontecía en los otros presidios ${ }^{81}$.

\footnotetext{
77 AHPLP, Ambrosio de Campos, leg. n. ${ }^{\circ}$ 930, f. ${ }^{\circ} 75$ r. Canaria, 27 de abril de 1592.

78 AHPLP, Ambrosio de Campos, leg. n. ${ }^{\circ}$ 930, f. ${ }^{\circ} 32$ v. Canaria 3 de febrero de 1592. Testamento de Cristóbal de Baena, vecino de Arjona; f. 90 r.: testamento de Miguel Ruiz de Toledo, vecino de Valladolid.

${ }^{79}$ AHPLP, Ambrosio de Campos, leg. n. ${ }^{\circ}$ 930, f. ${ }^{\circ}$ 90. Este soldado, que en noviembre de 1591 llevaba sirviendo dos años y medio, reconocía no haber cobrado el total de su servicio.

80 AHPLP, Francisco Suarez, leg. n. ${ }^{\circ}$ 902, f. ${ }^{\circ} 848$ v. En Canaria, dentro del hospital de San Martín, a 15 de febrero de 1590.

${ }^{81}$ AGS, Guerra y Marina, leg. 353, 27. En 6 de junio de 1592.
} 
Algunos, los menos, se casan en Las Palmas y mantienen, en función de su elección, cierta vida de desahogo, como así les aconteció a los dos artilleros, especialmente a Diego Ternero, que casó con la vecina de Las Palmas Beatriz Gutiérrez, con la cual hubo cuatro hijos ${ }^{82}$. Este, el 1 de julio de 1596 otorgaba su última voluntad por estar enfermo, aunque había tenido una magnifica actuación en la defensa de la ciudad cuando el ataque de Drake. Por las mandas fúnebres y por los deudores y acreedores que encontramos en su testamento observamos que tenía una posición desahogada, a pesar de reconocer que cuando se casó ninguno de los dos llevó al matrimonio ningún capital ${ }^{83}$. Asimismo, reconocía que la ciudad le adeudaba de su oficio de artillero todo lo que había corrido desde enero de 1591 hasta la fecha, 1 de julio de 1596. En el tiempo que vivió en Las Palmas construyó su morada en Triana, unas casas bajas, que habian edificado sobre un solar que habian comprado al escribano público Lorenzo de Palenzuela, que lindaba con casas del cantero Luis Báez, el mismo que le había levantado su morada, y con las propias del canónigo Cairasco. Asimismo, poseía otra casa en Tenerife, en La Orotava. Para cumplir su voluntad nombra como su albacea al otro artillero que residía en la isla, Juan Negrete. Otros casados en Las Palmas con mujeres de la tierra fueron algunos de los soldados, como Pedro de la Raya, que se desposó con Francisca Rodríguez, hija de Andrés Hernández y Andresa Rodríguez, vecinos de Las Palmas, a quien nombra por su heredera.

El equipamiento que traían algunos, además de su ropa, donde entraban camisas, calzones, jubones, herrezuelos, sombreros, medias, zapatos y borceguíes, entre otras cosas, constaba de un arcabuz con sus frascos, dagas y una espada ${ }^{84}$ con su pretina y vaina, que, a veces, dada la precariedad tenían que empeñar o dejar como manda para suplir los gastos que pudiera ocasionar su sepultura y oficios divinos que demandan a sus albaceas que les dijeran ${ }^{85}$, a la vez que también recuerdan en su voluntad a sus camaradas fallecidos, a los cuales encargan les digan misas por sus almas ${ }^{86}$. Los hubo, incluso, que se alistaron en posesión de un caballo, como el soldado Pedro de la Raya, quien declara haber vendido un caballo de su propiedad a un vecino de Las Palmas, por necesidad que tenia ${ }^{87}$.

Esta tropa que conformaba el presidido tenía un coste anual de 12.363.000 maravedís, cuya distribución correspondía a Juan del Hoyo, que debía llevar con toda pulcritud y puntualidad cuenta y razón de todo. Su gestión no fue todo lo diligente que se le exigía, a pesar de que de continuo se le apercibía por sus incumplimientos, que provocaban retrasos en el pago de haberes a la tropa. Así, el soldado de Baena, de la compañía de don Alonso de la Cueva,

\footnotetext{
${ }^{82}$ AHPLP, Francisco Suárez, leg. n. ${ }^{\circ} 907$, f. $^{\circ} 295$ r.

${ }^{83}$ AHPLP, Francisco Suárez, leg. n. ${ }^{\circ} 907$, f. ${ }^{\circ} 295$ r.

84 Entre otros tenía en su poder una espada el soldado Gonzalo Ruiz, de la compañía de Gaspar Fernández (AHPLP, Francisco Suárez, leg. n. ${ }^{\circ}$ 905, f. ${ }^{\circ} 121$ r.).

85 AHPLP, Francisco Suárez, leg. n. ${ }^{\circ} 903$, f. ${ }^{\circ} 41 \mathrm{r}$,

86 AHPLP, Francisco Suárez, leg. n. ${ }^{\circ} 903$, f. ${ }^{\circ} 118$ v. El soldado mosquetero Juan Ximénez, en su testamento otorgado el 5 de abril de 1592, manda que se diga por el alma de Mateo González, soldado, su camarada, tres misas rezadas y se pague de sus bienes por lo que le debía. 87 AHPLP, Ambrosio de Campos, leg. n. ${ }^{\circ}$ 930, f. ${ }^{\circ} 70$ r.
} 
declara en una manda de su testamento que desde que habia entrado al servicio de la compañia y llegado a la isla no había recibido nada a cuenta de sus servicios ${ }^{88}$. Los retrasos en los pagos fueron continuos, hasta el punto de que la relación del sueldo de los soldados, desde julio de 1589 hasta fines de diciembre de 1591, no había sido emitida en aquella última fecha ${ }^{89}$.

El pago de alojamiento y de los servicios que debía soportar el Cabildo hasta la rapiña de los soldados, ocasionada en este caso por el impago de sus servicios, tal como denuncian los soldados en distintas ocasiones, hizo que influyera en la población y en el despoblamiento de determinadas zonas de la ciudad, razón por la cual el rey, mediante distintas órdenes reales, estableció el pago, a costear por los Concejos de las islas, de una cantidad para cada soldado establecida en 8 reales por boca, que era la unidad por la cual se le pagaba al resto de los oficiales. Así, al capitán general correspondian 36 bocas, 24 por su persona y 12 por doce alabarderos de su guardia cada mes, que ascendia a 192 reales; los capitanes percibian cinco bocas cada uno, 40 reales por persona; los alféreces, 4 bocas equivalentes a 32 reales; los sargentos, 3 bocas; los capellanes y demás oficiales soldados, una boca, salvo que el capellán que cumpliera las funciones de administrador del hospital recibiría una boca más; el veedor y contador de la gente de guerra, 5 bocas, lo mismo que el pagador; el médico, 4 bocas; y el cirujano, una, mientras que el sargento mayor nombrado por el rey en la isla —en este caso era Juan de Ocaña ${ }^{90}$ _, 2 bocas. A esto se añadía una boca más al maestro de artillero Juan Negrete ${ }^{91}$.

El alojamiento y la actitud de los soldados en los lugares de la ciudad generaron denuncias ${ }^{92}$, que se ampliaron con las fechorias cometidas por los soldados en la ciudad de Las Palmas, disminuyendo así su crédito a la vez que atemorizaban a la población, pues de continuo hacian gracietas y actos que causaban escándalo público.

Los hijos del capitán general fueron algunos de los protagonistas de estos actos. Así, el alférez Juan de la Cueva fue procesado por poner colgados a la puerta del oidor Rodrigo de Cabrera, enemigo del capitán general, varios pares de cuernos, razón por la cual se le instruyó una causa, que terminó en Madrid, lugar a donde se remitió el sumario para que resolviese el Consejo de Guerra ${ }^{93}$. El otro hijo, don Alonso de la Cueva, capitán de una de las compañias, cometió un delito mayor al raptar en 1592, con la colaboración de Gaspar Villalta, caballero avecindado en la isla, a Marina de San Juan, doncella que había

88 AHPLP, Ambrosio de Campos, leg. n. ${ }^{\circ}$ 930, f. ${ }^{\circ} 32$ v. Canaria, 3 de febrero de 1592.

89 AGS, Consejo y Junta de Hacienda, leg. 302, f. ${ }^{\circ}$ 15, doc. 3; leg. 304 f. ${ }^{\circ} 12$, doc. 3 ; y f. ${ }^{\circ} 15$, doc. 7 .

90 AGS, Guerra y Marina, leg. 427, f. ${ }^{\circ}$ 78. El sargento mayor falleció el 1 de abril de 1595, según certificación del escribano del concejo Francisco de Casares. A este sucedió como sargento mayor Jerónimo de Aguilera, que lo era por nombramiento real de Fuerteventura.

${ }^{91}$ LOBO CABRERA, M. y F. BRUQUETAS DE CASTRO: El ingeniero militar Próspero Casola..., op. cit., doc. 20, pp. 262-263. "Orden que don Luis de la Cueva y Benavides dexó en lo tocante al servicio y utensilios de la gente de guerra que preside en las yslas de Canaria». Orden de 21 de octubre de 1592, dada en Canaria.

92 JIMÉNEZ ESTRELLA, Antonio: "La otra violencia. Presencia militar y conflictos con la población civil en Castilla (siglo XVI)", en LOZANO NAVARRO, Julián, y Juan Luis CASTELLANO (eds.): Violencia y conflictividad en el universo barroco, Granada, 2011, p. 97.

93 AGS, Diversos de Castilla, leg. 13-58 
venido de Sevilla en compañia del notario del tribunal del Santo Oficio de la Inquisición, Juan Martínez de la Vega y su mujer, por lo cual se le abrió un proceso por el tribunal inquisitorial ${ }^{94}$. A ello se unieron otros atropellos cometidos por los soldados del presidio, que fueron denunciados por el propio capitán general al Consejo. Así, por provisión real el monarca entendía la denuncia presentada por don Luis en razón con las fechorias cometidas por algunos de los soldados del presidio, entre ellas el haber robado algunas cabras, después de haber herido a su dueño, forzados por la nesçesidad, y aprobaba el castigo dispuesto a aquellos, al tiempo que autorizaba al general, para evitar dichos desórdenes, a acomodarlos de alojamiento con el servicio y utensilio de agua, leña, manteles y luz, según se acostumbraba en todas las partes donde existía gente de guerra, siempre y cuando se procediese con la menor vejación para los naturales de las islas ${ }^{95}$.

Estos inconvenientes ocasionaron que las autoridades de Gran Canaria se quejaran reiteradamente, tanto del nuevo nombramiento de capital general como de los soldados profesionales, en especial por el asentamiento de las tropas en la ciudad de Las Palmas, razón por la cual una parte importante de ellos - se estima que unos 240, toda vez que un año antes se calculaba que el presidio lo formaban 490 hombres96_ abandonó la isla rumbo a la península ${ }^{97}$, aunque algunos se quedaron definitivamente en Gran Canaria, pues al poco de llegar enfermaron y murieron tras ser alojados en el hospital de San Martín 98 , dejando sus bienes a dicha institución para que acogiera sus restos $^{99}$; mientras, otros señalan como lugar donde repose su cuerpo la catedral de Santa Ana ${ }^{100}$. No obstante, hasta el final de su mandato don Luis contó con una guarnición cercana a los 250 soldados, tal como informa el corregidor Tomás de Cangas a sus superiores ${ }^{101}$.

Caso aparte son aquellos soldados que antes de partir para el socorro de Fuerteventura otorgan sus testamentos, los cuales señalan que si en tal expedición muriesen piden se les entierre en la ermita e iglesia más cercana a su lugar de finamiento, y se les celebren los oficios pertinentes en las iglesias y conventos de la isla de Gran Canaria ${ }^{102}$. En el mismo caso se encuentra Juan Clavijo, soldado de la compañía del capitán Luis de Benavides, quien en

\footnotetext{
${ }^{94}$ RUMEU DE ARMAS, A.: Piraterias y ataques navales..., op. cit., t. II, segunda parte, p. 610. 95 LOBO CABRERA, M. y F. BRUQUETAS DE CASTRO: El ingeniero militar Próspero Casola..., op. cit., doc. 17, p. 256. Provisión real fechada en El Pardo a 28 de octubre de 1591.

96 Esta cifra es la misma que queda recogida en una certificación fechada el 7 de agosto de 1592. Vid. SUÁREZ GRIMÓN, V., y P. QUINTANA ANDRÉS: «Instituciones y grupos de poder en Canarias en el siglo XVI: Cabildos secular y eclesiástico", en Felipe II, el Atlántico y Canarias, Las Palmas de Gran Canaria, 2000, p. 221.

$97 \mathrm{El}$ veedor y contador Juan del Hoyo, tras examinar una revista de 30 de abril de1592. estimaba en 490 las plazas del presidio (incluidas las de oficiales y los soldados enviados a otras islas).

${ }^{98}$ Entre otros, otorga su testamento estando en el hospital de San Martín Lázaro Moreno, natural de Baeza, y Miguel Sánchez, sevillano. AHPLP, Francisco Suárez, leg. n. ${ }^{\circ}$ 902, fols. 823 v. y 848 v. Año 1590.

99 AHPLP, Francisco Suárez, leg. n. ${ }^{\circ} 904$, f. $^{\circ} 60$ r,

100 AHPLP, Ambrosio de Campos, leg. n. ${ }^{\circ}$ 930, f. ${ }^{\circ} 70$ r. Así los dispone el soldado Pedro de Raya, cuyo nombre de alistamiento era Luis de Carmona.

101 AGS, Diversos de Castilla., leg. 13, f. ${ }^{\circ} 56$ (Carta de 4 de octubre de 1593).

102 AHPLP, Teodoro Calderín, leg. n. ${ }^{\circ}$ 900, fols. 423 v. y 431 r.
} 
noviembre de 1593 otorga su última voluntad por estar de viaje a Berbería y temerse de la muerte, seguramente para intentar rescatar a los cautivos que los moros se habian llevado de Fuerteventura, pues declara que va de armada ${ }^{103}$.

Los soldados, según sus apreciaciones, nunca se encontraron a gusto en Canarias, pues apenas tuvieron actividad en los años que residieron en Gran Canaria, salvo el episodio de Fuerteventura; a ello se une que muchos enfermaron al poco de llegar a la isla, sin contar los inconvenientes que sufrieron para el alojamiento, la pobreza - pues se les pagaba tarde y mal-, especialmente por la carestía de la tierra, que era tónica dominante, tanto en mantenimientos como en vestidos, razón por la cual los vecinos se negaban a alojarlos, pues las casas no estaban acomodadas para recibirlos, eran pequeñas y ruines, e incluso algunos tenían que dormir en el suelo ${ }^{104}$, a causa de lo cual habia resultado que muchos enfermaran y muriesen.

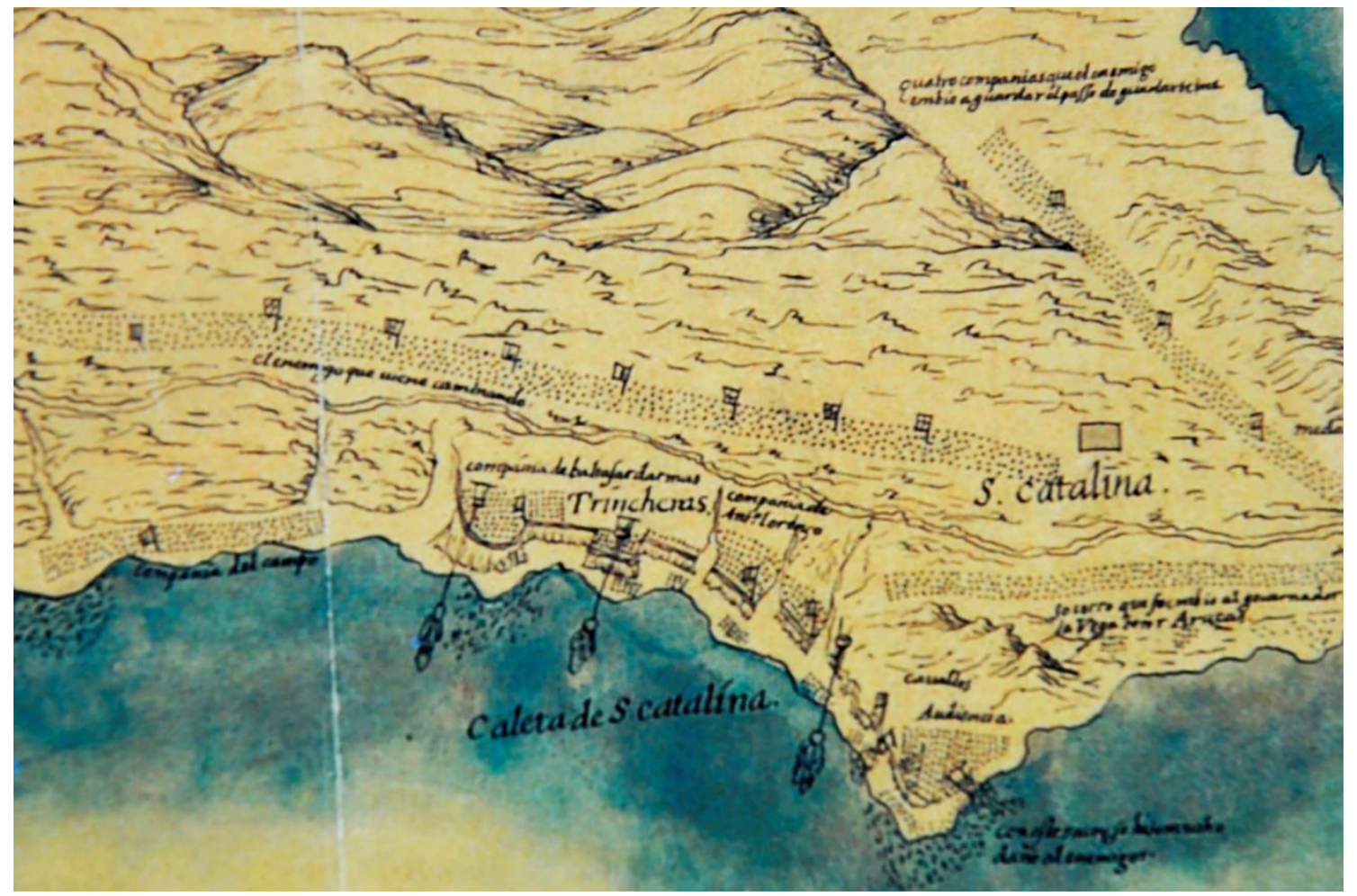

Imagen: Disposición de varias compañias de milicias en la zona costera cercana a Santa Catalina frente a los atacantes holandeses en 1599 [Las Palmas de Gran Canaria a través de la cartografia..., op. cit., p. 51].

Las continuas denuncias y el malestar de los vecinos derivaron en que se eligiera como zona para la ubicación de los soldados el barrio de Triana, en torno a la calle que bajaba de San Francisco al pilar y fuente de Triana y desde el monasterio de la Concepción bernarda en dirección a la misma calle. Con ese objeto se mandó desalojar muchas de las casas ubicadas en dicho perímetro, a excepción de aquellas donde vivian pescadores y mareantes. El alquiler de las citadas casas tenía que abonarlo el Cabildo grancanario, razón

103 AHPLP, Francisco Suárez, leg. n. ${ }^{\circ}$ 904, f. ${ }^{\circ} 520$ r.

104 AGS, Guerra y Marina, leg. 253, f. ${ }^{\circ}$ 207. Carta de D. Luis de la Cueva (1 de noviembre de 1589), y leg. 280, f. ${ }^{4}$ 49. Carta del capitán general al rey (15 de enero de 1590). 
por la cual la oposición iba creciendo a medida que la situación se alargaba ${ }^{105}$. Por ello se ajustó el valor de la renta de 81 viviendas para alojar a los soldados en aquel entorno, donde en 1590 se ubicaron 367 soldados, dos capitanes, dos alféreces y tres sargentos, integrantes de las tres compañias, cuyos jefes eran los capitanes Juan Fernández de Viedma, Gaspar Fernández de Ayala y Juan Xaraquemada ${ }^{106}$.

Además de estar alojados en casas propias, desalojadas para ser ocupadas por la tropa, otros vivieron en domicilios de vecinos, con los que llegaron a tener buena relación, hasta el punto de que en sus testamentos agradecen los servicios prestados, tanto cuando estaban sanos como cuando se hallaban enfermos. Así, el soldado Juan Gutiérrez Arroyo reconoce deber a la vecina María Hernández cierta cantidad de dinero por haber estado en su casa y haberle curado durante su estancia ${ }^{107}$.

En otra ocasión es la vecina María de Troya la que en 1596 daba poder al sargento mayor para que cobrara del Concejo 83 reales que se le debían por 27 días que había tenido en su casa alojados a los alféreces y soldados que habian venido a la isla, especialmente en darles cama a razón de 3 reales por noche ${ }^{108}$.

Además, a esto se añadía, por una orden real emitida el 21 de octubre de 1592, la autorización a don Luis de la Cueva para que en las islas se diese a la infantería que en ella residia de guarnición el servicio de utensilios, entre los que se incluía: una cama de madera con un colchón lleno de lana, dos sabanas, una frazada, un cabezal - con la obligación de cambiarle la ropa blanca de ocho en ocho dias en verano y de quince en quince en invierno-; asimismo una mesa con dos banquillos y escabeles, una tabla de manteles, dos servilletas, una toalla para secarse el rostro y el lavado de la ropa de ocho en ocho dias, menaje de seis platos (tres grandes y tres pequeños), dos jarros (uno para vino y otro para agua), un barril de vino, un jergón para la guardia, una caja de madera con su llave -donde pudieran guardar los manteles y las servilletas, junto con el pan y otras cosas de comer-, un candelero de latón o madera, un candil, una olla, una linterna, un asador, una cuchara de hierro o de palo, un acetre o caldera para sacar agua con su cuerda, un mortero de piedra o palo con su mano, un lebrillo para lavar los platos, cuatro cargas de leña cada mes para guisar. Todo este menaje debían costearlo los Cabildos, dividido entre las islas: Tenerife la mitad, y la otra mitad en tres tercios: uno Gran Canaria, otro La Palma y el restante el resto de las islas ${ }^{109}$.

105 AGS, Guerra y Marina, leg. 294, f. ${ }^{2}$ 205. RODRÍGUEZ YANES, J. M.: Defensa, reclutas..., op. cit, vol. I, pp. 70 y 381.

106 RODRÍGUEZ YANES, J. M.: Defensa, reclutas..., op. cit., vol. I, p. 382.

107 AHPLP, Francisco Suárez, leg. n. ${ }^{\circ}$ 902, f. ${ }^{\circ} 361$ r. En Canaria, a 19 de enero de 1591.

108 AHPLP, Andrés Rosales, leg. n. ${ }^{\circ}$ 934, f. ${ }^{\circ} 174$ v. Todavía en 1596 se le adeudaban a esta vecina el costo del alojamiento.

109 LOBO CABRERA, M. y F. BRUQUETAS DE CASTRO: El ingeniero militar Próspero Casola..., op. cit., doc. 20, pp. 259-261. "Orden que don Luis de la Cueva y Benavides dexó en lo tocante al servicio y utensilios de la gente de guerra que preside en las yslas de Canaria». 
No obstante, los soldados que habian quedado en Gran Canaria después de haberse ido don Luis destinado a Galicia se quejaban al rey, por carta fechada en 21 de diciembre de 1595, de que después de haber partido el capitán general los vecinos no les habían entregado nunca el servicio y alojamiento que les daban antes, por lo que pedian que se les pagara tal como se solia hacer en todas las partes donde el rey tenía soldados ${ }^{110}$.

Una vez que se había trasladado a la península don Luis de la Cueva y

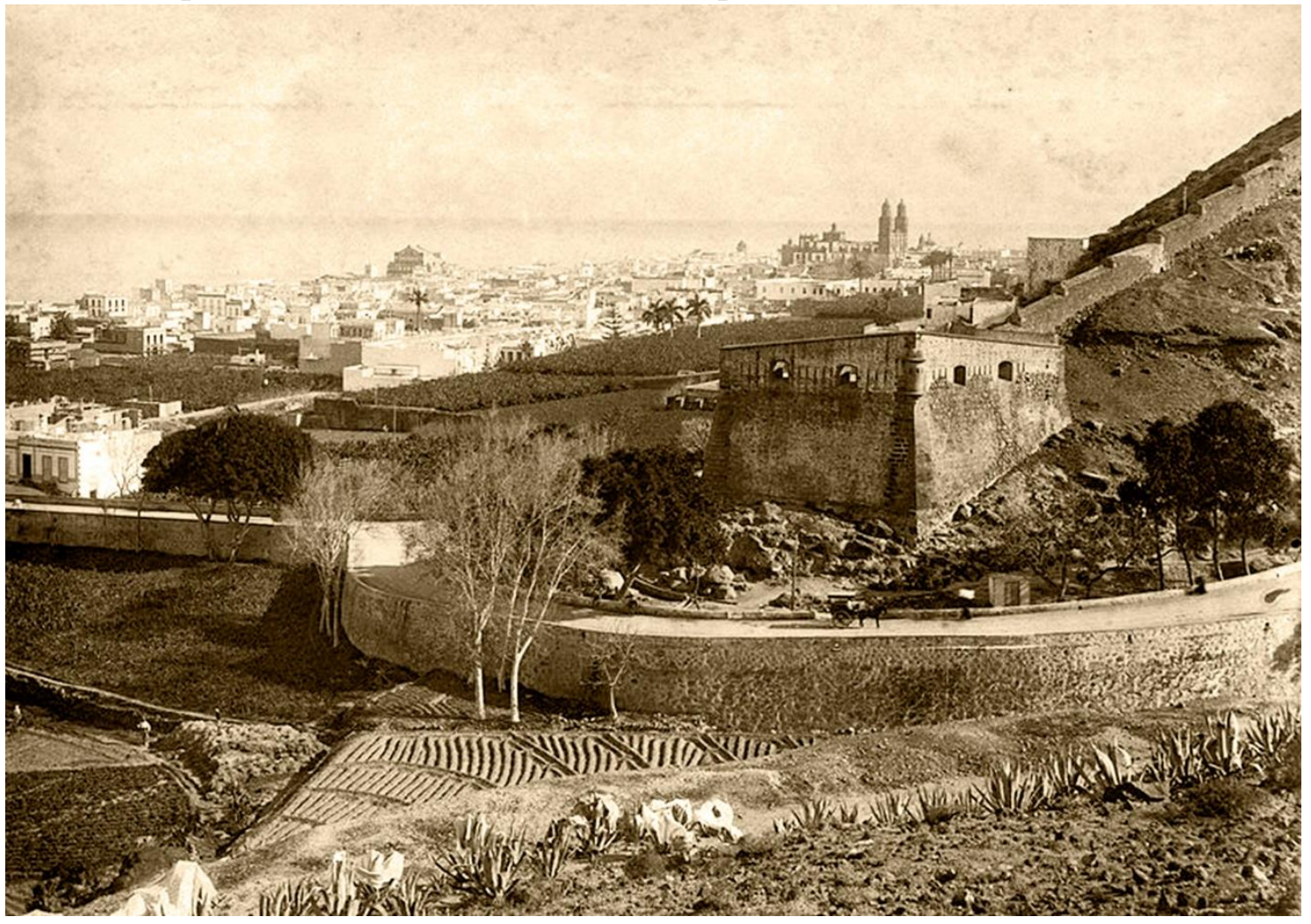

Imagen: Castillo de Mata (Las Palmas de Gran Canaria)

(Imagen de dominio público).

haberse vuelto al régimen anterior al nombramiento del capitán general, y en el ínterin que se nombraba al nuevo gobernador, cuyo cargo recayó en el capitán Alonso Alvarado, se hizo cargo de las milicias y de los soldados de presidio que quedaron en la isla el regente doctor Arias, oidor de la Audiencia. En escrito que envía al rey en 11 de mayo de 1595, dio cuenta del alarde general que habia hecho de los naturales de la isla, al que comparecieron 1.800 hombres, 693 arcabuceros y 1.108 de lanzas y alabardas y 50 de a caballo, así como comunicó las necesidades armamentísticas, razón por la cual solicitaba al monarca 1.000 arcabuces y mosquetes para que la gente estuviese bien armada y la tierra puesta en defensa, asegurando que así habría más seguridad que con el presidio, pues mientras había estado este en Gran Canaria los naturales habian olvidado el ejercicio de la guerra, por entender que no estaba a su cargo la defensa de la tierra ${ }^{11}$.

110 AGS, Guerra y Marina, leg. 444, f. ${ }^{\circ}$ 129. "Los soldados de la isla de Canaria".

111 AGS, Guerra y Marina, leg. 427, f. ${ }^{\circ}$ 76. Carta del regente de la Audiencia, doctor Arias, a Felipe II, de 11 de mayo de 1595. 
Meses más tarde, posesionado de su cargo como gobernador de Gran Canaria, Alonso Alvarado daba una visión bien distinta de la del regente de la Audiencia, considerando además la importancia de la presencia del presidio en una isla que de continuo vivía sobresaltada por los anuncios que llegaban de los posibles ataques de ingleses y berberiscos. En un exhaustivo informe que envia a Felipe II en 27 de junio de 1595 expresaba que, recién llegado a la isla, habia dispuesto una muestra general de la gente de la isla con concurrencia en Las Palmas de 1.200 hombres con capacidad para pelear, aunque muchos desarmados y otros con muy pocas armas; y lo peor, con muy mala práctica y peor disciplina, razón por la cual los juzgaba muy torpes, en especial porque la mayor parte de la gente vivia fuera de la ciudad, en el campo, ocupados en sus granjerias y labores, a dos, cuatro y seis leguas de la ciudad.

Dicho razonamiento le hacía convenir, y así se lo exponía abiertamente al monarca, que no había sido debidamente informado acerca de la salida del presidio de la isla, por ser como era el archipiélago frontero de enemigos, de tal modo que los que lo aconsejaron

fue por sus particulares intereses, los unos movidos de pasión y los otros por pareçerles que no tenian tanta mano y autoridad con sus oficios, y las demás yslas lo hazian por escusarse de pagar el servicio y aloxamiento.

Con estas razones, más la impresión que había concluido respecto a la defensa de la isla, que está muy aventurada y muy flaca para defenderse, propuso la necesidad de los 400 soldados de presidio, para que de ordinario estuvieran con las armas en la mano para hacer frente a los enemigos ${ }^{112}$.

112 AGS, Guerra y Marina, leg. 428, f. ${ }^{\circ} 191$. 
ANEXO

NÓMiNa DE SOLDADOS ${ }^{113}$

\section{Compañia del capitán don Alonso de la Cueva y Benavides}

Alférez: Don Luis de Benavides.

Luis de Robres.

Sargento: Juan de Medina.

Soldados: Cristóbal de Baena, soldado, v. ${ }^{\circ}$ de Arjona.

Lorenzo Muñoz, soldado.

Pedro Sánchez, soldado.

Juan de Santiago, soldado.

Francisco de Mármol, soldado.

Miguel Ruiz de Toledo, v. ${ }^{\circ}$ de Valladolid, soldado.

Juan de la Cuesta, soldado de la compañía de Baeza, Jaén.

Gonzalo de Herrera, cabo de escuadra de su compañia.

Pedro de la Raya (cambió el nombre por Luis de Carmona), natural de la Torre de Pedro Gil, Úbeda.

Juan Alonso, soldado.

Luis de Valdés, soldado.

Juan de Arévalo, cabo de escuadra que fue de la compañía.

Francisco Navarrete, capellán.

Compañia de Juan de Xaraquemada
Sargento Polo
Cabos: Diego Hernández, cabo de escuadra.
Alonso de Lara, soldado arcabucero, cabo de escuadra.
Juan Martínez de la Manchilla, soldado, de Jaén
Miguel..., soldado.
Gaspar, soldado.
Juan Ximénez, soldado y mosquetero.
Sebastián de la Raya, soldado, natural de Sabrote.
Juan de Burgos, soldado.
Lorenzo de la Risa, soldado.
Francisco Hernández de Yeste, difunto, soldado.

113 Estos soldados los hemos registrado a través de los protocolos notariales de Las Palmas entre 1590 y 1598. 


\section{Compañia de Juan Fernández de Viedma}

Antón Chiquero, cabo de escuadra.

Francisco de Acosta Flores, capellán.

Miguel Sánchez, sevillano, mosquetero.

Soldado de la compañía del capitán Juan Fernández de Viedma.

Juan Gutiérrez de Arroyo, soldado. Al morir Viedma pasó a la compañía de Alonso de la Cueva.

\section{Compañia de Gaspar Fernández}

Lázaro Moreno, natural de Baeza, soldado y arcabucero en ella. Pedro, su tambor.

Francisco Hernández, soldado, de Madrid.

Alonso de Bustamante, soldado.

Gonzalo Ruiz, natural de Arjona.

Francisco Hidalgo, soldado.

Pedro de la Vega, soldado.

Zoilo de Ochoa.

Juan Perestelo, soldado.

Juan de la Cruz, soldado.

Andrés de..., soldado.

\section{Compañia de Luis de Robres y Benavides, capitán de infanteria}

Alonso Pérez, natural de Guadix.

Bernabé Dejo.

Juan de Morales, soldado.

Bartolomé Montoro, natural de Bujalance.

Juan Clavijo 


\section{Otros}

Francisco de Navarrete, capellán de su señoria

Juan de Osuna, cabo de escuadra.

Miguel de Navidad, cabo de escuadra.

Pedro de Matos, cabo de escuadra.

Marcos Martín.

Juan de Rubián.

Sorota.

Hernando de Balboa.

Juan...

Alonso de Cosar, soldado.

Pedro montañés, soldado.

Luis de Coçar.

Antonio Tamayo, soldado.

Alonso Jurado.

Gaspar Garrido.

Miguel de Vilches, soldado.

Juan Cortés.

Alonso Granado.

Juan de Soto.

Antonio de Torres.

Bartolomé Narváez.

Mateo González, soldado.

Lorenzo de la Rocha, soldado.

Don Jerónimo Manso.

Andrés Ruiz.

Gabriel de Çabiente.

Antonio Hinojosa, soldado.

Mateo López, soldado.

Andrés Santos.

Andrés Vizcaíno.

Juan Pérez de San Diego.

Cristóbal Muñoz.

Francisco de Lima, soldado.

Miguel de Nava, soldado.

Juan de la Cuesta de la compañía de Baeza.

Pedro de Torres, natural de Martos ${ }^{114}$.

114 Soldado del presidio que desfiló en el décimo auto de fe celebrado en Las Palmas en 1591. 
Juan Diaz Romo, de Madrigalejos ${ }^{115}$.

Juan Rodríguez de Andújari116.

Juan Fernández de Galicia117,

Francisco Martínez de Ávila118

Juan Senero de Jaén ${ }^{119}$.

Don Juan de Mendoza.

Don Juan de la Puerta.

\section{Bibliografia}

ÁLAMO MARTEL, M. D.: El capitán General de Canarias en el siglo XVIII, Las Palmas de Gran canaria, 2000.

BORREGUERO BELTRÁN, C.: "El ejército del rey", en O`DONNELL, H. (dir.): Historia militar de España. III. Edad Moderna..., Madrid, 2013, t. 2, pp. 119-153.

CASTILLO DE BOVADILLLA, J.: Politica para corregidores y señores de vasallos en tiempos de paz y guerra, Madrid, 1775.

CONTRERAS GAY, J.: "Las milicias en el Antiguo Régimen. Modelos, características generales y significado histórico", Chronica Nova, 20, Granada, 1992, pp. 75-103.

DARIAS PADRÓN, D.: "Sumaria historia orgánica de las milicias de Canarias", El Museo Canario, ns. 12, 14 y 16, Las Palmas de Gran Canaria, 1951, 1953 y 1955, pp. 99-208, 131-204, y 1-37.

JIMÉNEZ ESTRELLA, Antonio: "La otra violencia. Presencia militar y conflictos con la población civil en Castilla (siglo XVI)", en LOZANO NAVARRO, Julián, y Juan Luis CASTELLANO (eds.): Violencia y conflictividad en el universo barroco, Granada, 2011, pp. 95-118.

LOBO CABRERA, M. y F. BRUQUETAS DE CASTRO: El ingeniero militar Próspero Casola y Canarias (Escritos, informes y descripciones), Las Palmas de Gran Canaria, 2014,

LOBO CABRERA, M.: Alonso Alvarado y Antonio Pamo Chamoso, Madrid, 2017.

MILLARES TORRES, A.: Historia de la Inquisición en las Islas Canarias, Las Palmas, 1874.

MILLARES TORRES, A.: Historia general de las Islas Canarias, Las Palmas, edic. de 1977, t. III.

O`DONNELL Y DUQUE DE ESTRADA, H.: "La táctica y la técnica españolas. El combate en sus diversos tipos", en O`DONNELL, H.: Historia militar de España. III. La Edad Moderna, t. 2, Madrid, 2013, pp. 154-187.

\footnotetext{
115 Soldado del presidio que desfiló en el décimo auto de fe celebrado en Las Palmas en 1591. 116 Soldado del presidio que desfiló en el décimo auto de fe celebrado en Las Palmas en 1591.

117 Soldado del presidio que desfiló en el décimo auto de fe celebrado en Las Palmas en 1591.

118 Soldado del presidio que desfiló en el décimo auto de fe celebrado en Las Palmas en 1591.

119 MILLARES TORRES, A.: Historia de la Inquisición en las Islas Canarias, Las Palmas, 1874, pp. $111-117$.
} 
RODRÍGUEZ YANES, J. M.: Defensa, reclutas y donativos en Canarias (15001735), Santa Cruz de Tenerife, 2018, vol. I.

RUMEU DE ARMAS, A.: "Don Pedro Cerón, Capitán General de la isla de Gran Canaria", El Museo Canario, 7, 17, Las Palmas de Gran Canaria, 1946, pp. 3-32.

RUMEU DE ARMAS, A.: Piraterias y ataques navales contra las Islas Canarias, Madrid, 1947-1950,

SOLBES FERRI, S.: "La defensa de las Islas Canarias en el siglo XVIII: modificaciones presupuestarias para su financiación", en GONZÁLEZ ENCISO, A. (ed.): Un Estado Militar. España, 1650-1820, Actas, Madrid, 2012, pp. 89-121.

SUÁREZ GRIMÓN, V. y P. QUINTANA ANDRÉS: "Instituciones y grupos de poder en Canarias en el siglo XVI: Cabildos secular y eclesiástico", en Felipe II, el Atlántico y Canarias, Las Palmas de Gran Canaria, 2000.

VIERA Y CLAVIJO, J. de: Extracto de las Actas del cabildo catedral de Canarias (1514-1791), Transcripción y estudio de Esteban Alemán Ruiz y Alexis Brito González, Las Palmas de Gran Canaria, 2007.

WARTELET, J. de: Diccionario militar, Madrid, 1863. 